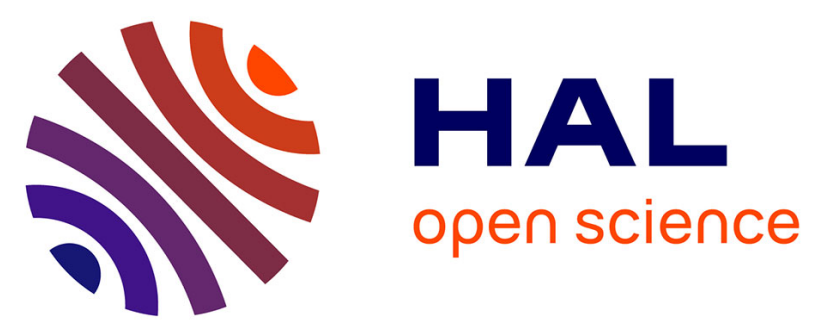

\title{
Structure and Dynamics of Water-Smectite Interfaces: Hydrogen Bonding and the Origin of the Sharp O-Dw/O-Hw Infrared Band From Molecular Simulations
}

Marek Szczerba, Artur Kuligiewicz, Arkadiusz Derkowski, Vassilis Gionis, Georgios D. Chryssikos, Andrey G. Kalinichev

\section{To cite this version:}

Marek Szczerba, Artur Kuligiewicz, Arkadiusz Derkowski, Vassilis Gionis, Georgios D. Chryssikos, et al.. Structure and Dynamics of Water-Smectite Interfaces: Hydrogen Bonding and the Origin of the Sharp O-Dw/O-Hw Infrared Band From Molecular Simulations. Clays and Clay Minerals, 2016, 64 (4), pp.452-471. 10.1346/ccmn.2016.0640409 . in2p3-01577621

\section{HAL Id: in2p3-01577621 \\ https://hal.in2p3.fr/in2p3-01577621}

Submitted on 9 Oct 2018

HAL is a multi-disciplinary open access archive for the deposit and dissemination of scientific research documents, whether they are published or not. The documents may come from teaching and research institutions in France or abroad, or from public or private research centers.
L'archive ouverte pluridisciplinaire HAL, est destinée au dépôt et à la diffusion de documents scientifiques de niveau recherche, publiés ou non, émanant des établissements d'enseignement et de recherche français ou étrangers, des laboratoires publics ou privés. 
Structure and dynamics of water-smectite interfaces:

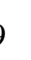

\section{from molecular simulations}

\section{Hydrogen bonding and the origin of the sharp $O-D_{w} / O-H_{w}$ infrared band}

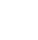

${ }^{1}$ Institute of Geological Sciences, Polish Academy of Sciences, Krakow, Poland

${ }^{2}$ Theoretical and Physical Chemistry Institute, National Hellenic Research Foundation,

Athens, Greece

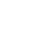

${ }^{3}$ Laboratoire SUBATECH (UMR 6457), Ecole des Mines de Nantes, Nantes, France

\section{${ }^{*}$ Corresponding author: $\underline{\text { ndszczer@cyf-kr.edu.pl }}$}

KEY WORDS: clay-water interface, adsorbed water, smectite, molecular dynamics, infrared spectroscopy 
ABSTRACT

Experimental studies have shown that a sharp high-frequency IR band at $\sim 3615 \mathrm{~cm}^{-1}$ (in $\mathrm{H}_{2} \mathrm{O}$ form) and at $\sim 2685 \mathrm{~cm}^{-1}$ (in $\mathrm{D}_{2} \mathrm{O}$ form) is a common feature for all smectites, and its position correlates with layer charge. In order to explain the molecular origin of this band in terms of total layer charge, charge localization, as well as nature of interlayer cations influencing the position and intensity of this peak, a series of classical MD simulations were performed for several smectite models. The smectite layers were described using a modified CLAYFF force field, where the intramolecular vibrations of $\mathrm{H}_{2} \mathrm{O}$ were more accurately described by the Toukan-Rahman potential. The power spectra of molecular vibrations of hydrogens were calculated for selected sub-sets of interlayer $\mathrm{H}_{2} \mathrm{O}$ to quantitatively analyze their contribution to the observed spectral features. The statistics of hydrogen bonds in the smectite interlayers were also analyzed to support the spectral calculations.

The simulation results demonstrated clearly that only the $\mathrm{H}_{2} \mathrm{O}$ molecules in close proximity with the smectite surface are responsible for the observed sharp vibrational band. Other hypotheses on the possible origins of this band were carefully considered and eventually rejected. Two orientations of $\mathrm{H}_{2} \mathrm{O}$ molecules donating one or two $\mathrm{H}$-bonds to the basal oxygens of the smectite surface (monodentate and bidentate orientations, respectively) are observed. In both orientations these $\mathrm{H}$-bonds are quite weak, pointing to a generally hydrophobic character of the smectite surface. Both orientations were found to contribute to the high-frequency band, but the monodentate orientation provides the predominant contribution because surface $\mathrm{H}_{2} \mathrm{O}$ molecules in this orientation are much more abundant. In good agreement with experiment, only a small difference in the peak position was observed between smectites with different charge localization. The effect of the total layer charge, i.e. the red-shift for higher charge smectites, was also confirmed. This shift arises from the decrease of the $\mathrm{H}$-bonding distances of $\mathrm{H}_{2} \mathrm{O}$ in monodentate and bidentate orientation. 
Fourier transform infrared spectroscopy (FTIR) is one of the most commonly used

techniques for studying clay minerals. However, unambiguous assignment of the vibrational bands originating from the stretching modes of adsorbed molecular $\mathrm{H}_{2} \mathrm{O}\left(\mathrm{O}-\mathrm{H}_{\mathrm{w}}\right)$ and structural $\mathrm{OH}\left(\mathrm{O}-\mathrm{H}_{\mathrm{s}}\right)$ in the clay materials is not always feasible. This is especially true for swelling clay minerals like smectites, which have large water sorption capacities (e.g., Cases et al., 1997; Sato et al., 1992) and may contain significant amounts of adsorbed water under air-dry conditions even upon prolonged drying (e.g., Środoń and McCarty, 2008).

Kuligiewicz et al. (2015a) have recently presented new evidence that the sharp highfrequency bands observed at $\sim 3610-3640 \mathrm{~cm}^{-1}$ involve a significant contribution from weakly hydrogen-bonded $\mathrm{O}-\mathrm{H}_{\mathrm{w}}$ of adsorbed $\mathrm{H}_{2} \mathrm{O}$ molecules. These observations were in agreement with earlier spectroscopic measurements (Russell and Farmer, 1964; Farmer and Russell, 1971; Suquet et al., 1977; Sposito and Prost, 1982; Cariati et al., 1981, 1983; Sposito et al., 1983), and opened the possibility for obtaining layer charge diagnostics based on the vibrational signature of $\mathrm{H}_{2} \mathrm{O}$ in smectite (Kuligiewicz et al., 2015b).

Early computational molecular modeling studies of clays (Skipper et al., 1991; Chang et al., 1995; Boek et al., 1995; Greathouse and Sposito, 1998; Sposito et al., 1999) suggested the existence of H-bonds between water and siloxane surfaces. This H-bonding implies a specific spatial arrangement of the surface $\mathrm{H}_{2} \mathrm{O}$ molecules with respect to oxygen atoms of the basal plane. These MD calculations confirmed the model of Prost (1975) with one O-H $\mathrm{H}_{\mathrm{w}}$ bond of the $\mathrm{H}_{2} \mathrm{O}$ molecule directed towards the clay surface, donating an $\mathrm{H}$-bond to the basal oxygen atom.

The existence of such interfacial H-bonding with one $\mathrm{O}-\mathrm{H}_{\mathrm{w}}$ bond oriented towards the clay surface was later confirmed by simulations of smectites and muscovite (e.g. Wang et al., 2005b, 2009; Marry et al., 2008, 2013; Morrow et al., 2013; Ngouana Wakou and Kalinichev, 
2014; Greathouse et al., 2015; Teich-McGoldrick et al., 2015; Zaunbrecher et al., 2015, Loganathan et al., 2016a, 2016b), using more sophisticated force fields, specifically optimized for clay mineral studies, such as CLAYFF (Cygan et al., 2004). The existence of an additional type of interfacial $\mathrm{H}_{2} \mathrm{O}$ located above the ditrigonal cavities of smecites and with both $\mathrm{O}-\mathrm{H}_{\mathrm{w}}$ bonds directed towards the basal surface was also reported for 2:1 sheet silicates of high total layer charge (Wang et al., 2005b, 2009). Ab-initio calculations showed that these Hbonds are relatively short-lived and weaker than typical $\mathrm{H}_{2} \mathrm{O} \cdots \mathrm{H}_{2} \mathrm{O}$ in liquid water (Boek and Sprik, 2003).

In addition, Suzuki and Kawamura (2004) calculated the theoretical FTIR spectra of water adsorbed on Na-beidellite with total layer charge of 0.33 per half unit cell (phuc). Based on their modeling, the $\mathrm{O}-\mathrm{H}_{\mathrm{w}}$ bonds pointing towards the surface of beidellite contribute to a vibrational band at $\sim 3500 \mathrm{~cm}^{-1}$, whereas the $\mathrm{O}-\mathrm{H}_{\mathrm{w}} \mathrm{H}$-bonded to other $\mathrm{H}_{2} \mathrm{O}$ molecules produce a band at $\sim 3365 \mathrm{~cm}^{-1}$. The relative intensity of the $\sim 3365$ to the $\sim 3500 \mathrm{~cm}^{-1}$ bands increased with increasing water content, and for $7 \mathrm{H}_{2} \mathrm{O}$ molecules phuc the band at $\sim 3500 \mathrm{~cm}^{-1}$ was no longer detectable.

The experimental and theoretical evidence of the hydrophobic character of the siloxane surface of uncharged clays has been broadly discussed in the literature (e.g., Michot et al., 1994, Bridgeman and Skipper, 1997; Arab et al., 2003; Tunega et al., 2004; Wang et al., 2004; 2005a; Churakov, 2006; Rotenberg et al., 2011; Šolc et al., 2011).However, for the siloxane surface of charged clays, like smectites, the picture is not as clear. Based on aromatic hydrocarbon adsorption experiments, Jaynes and Boyd (1991) have classified this surface as mostly hydrophobic. On the other hand, Sobolev et al. (2010) have used neutron scattering technique to determine that the surfaces of smectite clays with tetrahedral substitutions are hydrophilic. The importance of the specific structural charge location within a clay layer for the existence of hydrophobic and hydrophilic patches on its surface has also been determined 
in Monte Carlo computer simulations (Sposito et al., 1999). The relative weakness of the Hbonds donated by the interlayer water molecules to the clay basal surface, compared to the typical strength of the $\mathrm{H}_{2} \mathrm{O} \cdots \mathrm{H}_{2} \mathrm{O}$ bonds in bulk liquid water can be considered as a molecular-scale indication of relative hydrophobicity of the smectite siloxane surface.

The present study is aimed at advancing the aforementioned discussion by adding new spectroscopic arguments. Vibrational spectra of interfacial water molecules in several smectites are calculated and carefully analyzed here on the basis of molecular dynamics simulations in order to identify, interpret and quantify the variability of the position of the sharp $\mathrm{H}_{2} \mathrm{O}$ vibrational band as a function of total clay layer charge, layer charge localization, and nature of the interlayer cations, as recently observed experimentally (Kuligiewicz et al., 2015a).

\section{METHODOLOGY}

\section{Smectite structures and MD simulations}

In order to explore systematically the effects of smectite composition, type of the interlayer cations and water content on the structure of interlayer $\mathrm{H}_{2} \mathrm{O}$, a series of $\mathrm{MD}$ simulations were performed on four models of dioctahedral smectites with a total layer charge of 0.3 or 0.5 phuc and octahedral (montmorillonitic) or tetrahedral (beidellitic) charge localization:

$$
\begin{aligned}
& \text { Beid03: } \mathrm{M}_{0.3}^{+}\left(\mathrm{Al}_{2.0}\right)\left(\mathrm{Si}_{3.7} \mathrm{Al}_{0.3}\right) \mathrm{O}_{10}(\mathrm{OH})_{2} \\
& \text { Beid05: } \mathrm{M}_{0.5}^{+}\left(\mathrm{Al}_{2.0}\right)\left(\mathrm{Si}_{3.5} \mathrm{Al}_{0.5}\right) \mathrm{O}_{10}(\mathrm{OH})_{2} \\
& \text { Mtm03: } \mathrm{M}_{0.3}^{+}\left(\mathrm{Al}_{1.7} \mathrm{Mg}_{0.3}\right)\left(\mathrm{Si}_{4.0}\right) \mathrm{O}_{10}(\mathrm{OH})_{2} \\
& \text { Mtm05: } \mathrm{M}_{0.5}^{+}\left(\mathrm{Al}_{1.5} \mathrm{Mg}_{0.5}\right)\left(\mathrm{Si}_{4.0}\right) \mathrm{O}_{10}(\mathrm{OH})_{2}
\end{aligned}
$$

The interlayer water content $\left(2.5,5.0\right.$ and $7.5 \mathrm{H}_{2} \mathrm{O}$ phuc $)$ and the type of the interlayer cation 
$\left(\mathrm{Na}^{+}, \mathrm{Cs}^{+}\right.$, and $\left.\mathrm{Ca}^{2+}\right)$ for selected water contents were used as additional variables.

The structural models of the smectites were built on the basis of the pyrophyllite crystal structure (Lee and Guggenheim, 1981), with isomorphic substitutions introduced at specific atomic sites. The $\mathrm{Mg} / \mathrm{Al}$ ordering in the octahedral sheets was set by maximizing the distance between $\mathrm{Mg}$ atoms, following the work of Ortega-Castro et al. (2010). The $\mathrm{Al} / \mathrm{Si}$ ordering in the tetrahedral sheet was random but following the Löwenstein rule, i.e. excluding Al-O-Al linkages (Löwenstein, 1954). The simulation supercell was $8 \times 4 \times 2$ unit cells in the $a$, $b$, and $c$ crystallographic directions, respectively $(\sim 41.6 \AA \times 36.1 \AA \times \mathrm{Z} \AA$; the value of $\mathrm{Z}$ varied in the $\sim 12.5-19.0 \AA$ range depending mainly on the amount of water in the interlayer space). The edge surfaces were not considered.

The atoms of the smectite structure were not fixed - i.e. they were allowed to move around their crystallographically determined positions according to the modeling force field used. Only one cation in one octahedral sheet was kept frozen in its position in order to keep 2:1 layers in place during the entire simulation span. Partial atomic charges and other interatomic interaction parameters of smectite layers were described using the CLAYFF force field (Cygan et al., 2004) with structural $\mathrm{OH}$ groups modified by introducing a more accurate Morse potential (Greathouse et al., 2009). Ewald summation was used to calculate the long range corrections to the electrostatic interactions and the cutoff distance was set at $10.0 \AA$. Non-electrostatic Lennard-Jones parameters of the interatomic interactions involving bridging oxygen atoms were modified after Ferrage et al. (2011) in order to improve the description of the interlayer water structure of hydrated smectites. The necessity of this modification was justified based on comparisons of experimental and calculated XRD and neutron diffraction data (Ferrage et al., 2011). However, unlike the original suggestion of Ferrage et al. (2011), only the parameters of surface oxygen atoms were modified in our work, because initial test simulations showed that the modification for all bridging oxygen atoms leads to a substantial 
and unrealistic deformation of the clay octahedral sheet if the cell volume is not constrained in the simulations at constant pressure, i.e., in the NPT statistical ensemble (see Supplementary materials). Additionally, the Lennard-Jones parameters of tetrahedral Si and tetrahedral $\mathrm{Al}$ in the clay structure were also modified to compensate for the increased size of the surface bridging oxygen atoms by applying the usual arithmetic mixing rules for the parameters of interatomic interactions (Table 1).

\section{$===$ Table 1 ===}

For a more accurate description of the vibrational properties of water molecules, the parameters of intramolecular interactions for $\mathrm{H}_{2} \mathrm{O}$ were taken from the work of Toukan and Rahman (1985) using the implementation proposed by Praprotnik et al. (2004). This allowed a more accurate description of the anharmonicity of the $\mathrm{O}_{\mathrm{w}}-\mathrm{H}_{\mathrm{w}}$ stretching vibrations in the calculated IR spectra in comparison to the simple harmonic vibrational terms of the original CLAYFF parameterization (Cygan et al., 2004).

NPT-ensemble MD simulations at constant pressure $(P=1 \mathrm{bar})$ and temperature $(T=300 \mathrm{~K})$ were performed for $2.0 \mathrm{~ns}$ with the time step of $1 \mathrm{fs}$, preceded by one temperature annealing cycle from $400 \mathrm{~K}$ to $300 \mathrm{~K}$ of $0.1 \mathrm{~ns}$. This long equilibration run was followed by a short $10 \mathrm{ps}$ data analysis run when atomic positions and velocities were recorded every $2 \mathrm{fs}$. Standard periodic boundary conditions were applied (e.g., Allen and Tildesley, 1987) and all simulations were performed using the LAMMPS molecular modeling program (Plimpton, 1995)

\section{Simulation analysis}

The MD-simulated structural data were used to calculate the distributions of angles formed by the dipole axis of interfacial $\mathrm{H}_{2} \mathrm{O}$ molecules with respect to a vector normal to the 2:1 surfaces (angle $\alpha$ ) as a function of the distance $z$ of $\mathrm{O}_{\mathrm{w}}$ from the plane of the basal 
bridging oxygens $\left(\mathrm{O}_{b}\right)$. The direction of the $\mathrm{H}_{2} \mathrm{O}$ dipole was defined as a vector from the oxygen atom $\mathrm{O}_{\mathrm{w}}$ to the central point between the two hydrogen atoms $\mathrm{H}_{\mathrm{w}}$ of the same molecule. As the $\mathrm{HOH}$ angle was allowed to vary in the flexible $\mathrm{H}_{2} \mathrm{O}$ molecular model used, this methodology introduces some small additional spread of the calculated angles. Additionally, the distributions of angles between a given $\mathrm{OH}$ bonds of $\mathrm{H}_{2} \mathrm{O}$ and a vector normal to the 2:1 surfaces were calculated as a function of the distance $z$ from the $\mathrm{O}_{\mathrm{b}}$ plane (angle $\beta$ ). The position of the plane of basal oxygen atoms was determined by the maximum of the atomic density distribution for these atoms, similarly to the previous studies (Wang et al., 2005b, 2009; Loganathan and Kalinichev, 2013; Szczerba et al., 2014, Ngouana Wakou and Kalinichev, 2014; Greathouse et al., 2015; Teich-McGoldrick et al., 2015 ; Loganathan et al., 2016a, 2016b). All these properties were calculated by averaging over the last $1 \mathrm{~ns}$ of the equilibrium MD simulation runs.

\section{Calculation of power spectra}

MD-simulated atomic trajectories can be used to calculate so-called power spectra (PS) of atomic vibrations that contain an entire distribution of the power (density of states) of all atomic motions in the simulated system in a function of vibrations frequency. With certain restrictions, these power spectra can be compared to the experimental vibrational spectra (e.g., Allen and Tildesley, 1987; Kleinhesselink and Wolfsberg 1992). The power spectra are obtained as Fourier transformations of the so-called velocity autocorrelation function (VACF), which, in turn, can be directly calculated from the MD-simulated dynamic trajectories of the atoms in the modeled system. The frequency of $\mathrm{H}_{2} \mathrm{O}$ stretching vibration is usually well captured by the VACF of the water hydrogen atoms (e.g., Kalinichev, 2001).

In the present work, normalized VACF based on the last $10 \mathrm{ps}$ period of every MD simulation run were calculated for selected hydrogen atoms with a moving window of $1 \mathrm{ps}$ 
from the equilibrium part of the MD trajectory recorded every 2 fs:

$$
\operatorname{VACF}(t)=\frac{\sum_{f=1, \text { sel.atoms }}^{n-n_{\mathrm{VACF}}} \sum \vec{v}_{f} \cdot \vec{v}_{f+t}}{\sum_{f=1, \text { sel.atoms }}^{n-n_{\mathrm{VACF}}} \sum \vec{v}_{f} \cdot \vec{v}_{f}}
$$

where $n$ - is the total number of windows, $n_{\mathrm{VACF}}-$ is the number of windows used in a particular calculation of VACF. The first sum in nominator and denominator corresponds to averaging over total number of windows minus the number of VACF windows. The second sum is calculated over all hydrogen atoms of water molecules, or their selected subset based on the distance of the respective $\mathrm{H}_{2} \mathrm{O}$ from the clay surface and the angle of $\mathrm{H}_{2} \mathrm{O}$ dipole orientation (or angle between one of $\mathrm{OH}$ groups of $\mathrm{H}_{2} \mathrm{O}$ and a vector normal to the 2:1 surface). The scalar products of instantaneous atomic velocities and their subsequent Fourier transformation into vibrational power spectra were calculated according to standard VACF and PS definitions (e.g., Allen and Tildesley, 1987; Kleinhesselink and Wolfsberg, 1992). For every VACF window, the determination of a $\mathrm{H}_{2} \mathrm{O}$ molecule as belonging to a selected position/orientation population was checked at the beginning and at the end of the VACF window. The chosen short duration of the analysis run (10 ps) is, nevertheless, long enough in respect to a typical H-bonding lifetime (0.8-0.9 ps; Kumar et al., 2007), but still short enough not to allow $\mathrm{H}_{2} \mathrm{O}$ to change significantly their positions in the interlayer with respect to the clay surface. At the same time, the relatively short time of the individual VACF window (1 ps) is comparable with a typical H-bonding lifetime, but still allows to probe the stretching dynamics of the selected $\mathrm{O}-\mathrm{H}_{\mathrm{w}}$ bonds (e.g., Kalinichev, 2001). The choice of both characteristic calculation times ensured that the H-bonding situation of each $\mathrm{H}_{2} \mathrm{O}$ molecule was included in a certain selected angle/position subset for VACF calculation.

In order to calculate the power spectra of $\mathrm{H}_{2} \mathrm{O}$ vibrations, a cosine Fourier transform of VACF for the water hydrogen atoms was performed as: 


$$
\operatorname{PS}(\omega)=\sum_{t=1}^{n_{\mathrm{VACF}}} \operatorname{VACF}(t) \cdot \cos \left(\frac{\pi}{n_{\mathrm{VACF}}} \cdot t \cdot \omega\right)
$$

The statistical noise was preliminarily reduced by applying a filtering function:

$$
\operatorname{VACF}(t)=\operatorname{VACF}(t) \cdot \exp (-t / \tau)
$$

where $\tau$ was set to 0.25 ps.

Due to the normalization of VACF, the intensity of the calculated power spectra can, therefore, be considered as proportional to the total number of $\mathrm{H}_{2} \mathrm{O}$ molecules selected for each calculation.

\section{RESULTS AND DISCUSSION}

\section{Characteristic features of MD simulations}

The composition and adsorbed water content of all simulated clay models are presented in Table 2 along with the resulting basal spacings. The $2 \mathrm{~W}$ model for Cs-smectite is purely hypothetical and does not correspond to any experimental or natural conditions (e.g., Ngouana Wakou and Kalinichev, 2014).

\section{$===$ Table $2===$}

The values of the calculated basal spacings closely match those obtained by modelling the experimental diffractograms: $d_{001 \_1 \mathrm{w}}=11.6-12.9 \AA d_{001 \_2 \mathrm{w}}=14.9-15.7 \AA$ and $d_{001 \_3 \mathrm{w}}=18-19$ $\AA$ (e.g., Dazas et al., 2015). The data show clearly that for the same water content and interlayer cation $\left(\mathrm{Na}^{+}\right)$the basal spacing $d_{001}$ decreases with increasing layer charge (e.g. $15.95 \AA$ for Mtm03Na_2W and 15.37 $\AA$ for Mtm05Na_2W). This trend is in agreement with literature data (e.g., Sato et al., 1992, Ferrage et al., 2005, 2007), whereas some variation is related also to the layer charge location. Substantial differences in basal spacings were also observed as a result of the replacement of interlayer cations from $\mathrm{Na}^{+}$or $\mathrm{Ca}^{2+}$ to $\mathrm{Cs}^{+}$(e.g., 
These differences were caused mainly by the increased size of the cation and by differences in hydration energies.

In agreement with other recent simulations (e.g. Wang et al., 2005b, 2009; Morrow et al., 2013; Ngouana Wakou and Kalinichev, 2014; Greathouse et al., 2015; Teich-McGoldrick et al., 2015; Zaunbrecher et al., 2015; Loganathan et al., 2016a, 2016b), a typical snapshot of the interlayer structure (Figure 1) illustrated that $\mathrm{H}_{2} \mathrm{O}$ molecules close to the siloxane surface tend to be specifically oriented. Within a distance of $<3.5 \AA$ between $\mathrm{O}_{\mathrm{w}}$ and the siloxane surface two such preferred orientations could be distinguished. The population closer to the surface corresponds to $\mathrm{H}_{2} \mathrm{O}$ with both $\mathrm{O}-\mathrm{H}_{\mathrm{w}}$ bonds pointing towards the surface (bidentate), whereas a more distant and more pronounced population is due to the $\mathrm{H}_{2} \mathrm{O}$ pointing only one of their $\mathrm{O}-\mathrm{H}_{\mathrm{w}}$ bonds towards the surface and the second one towards the bulk of the interlayer (monodentate). In order to quantify these differences, these two populations were investigated as a function of smectite charge, type of the interlayer cations, and degree of hydration. 


\section{Position of the cations in the interlayer space}

The distribution of interlayer cations for different smectites (blue solid lines in Figures 2 and 3) exhibited a clear dependence on the amount and location of layer charge, as well as on the type of the cation. In the case of $1 \mathrm{~W}$ sodium smectites, two separate maxima were visible, each corresponding to inner-sphere coordination of $\mathrm{H}_{2} \mathrm{O}$ to the surface. For $2 \mathrm{~W}$ sodium structures, a strong tendency to form a third maximum corresponding to fully hydrated cations (outer sphere) in the middle of the interlayer was observed. The ratio between the central and wing (inner sphere) cation distributions depended on the charge location, whereas changes in total charge had similar effect on both of these maxima. This result is in agreement with other recent simulations and is supported by calculated XRD data (Dazas et al., 2015; Teich-McGoldrick et al., 2015). In the case of 3W structures, outer-sphere sodium ions formed two maxima close to the interlayer center instead of one as in $2 \mathrm{~W}$. The data for the Mtm03Na_3W structure were very similar to the results presented by Dazas et al. (2014). With increasing tetrahedral charge a tendency to form higher amount of inner-sphere complexes with the siloxane surface was observed.

The effect of changing interlayer cation from $\mathrm{Na}^{+}$to $\mathrm{Ca}^{2+}$ was investigated for the models with $2 \mathrm{~W}$ hydration. Comparison of smectites in $\mathrm{Ca}^{2+}$ form (Figure 3) with those in $\mathrm{Na}^{+}$form (Figure 2) indicated that, despite the two-fold increase in the cation hydration enthalpy, the only effect was the vanishing of the (already weak) population of cations in the vicinity of the surface. The only exception was Beid05Ca_2W, for which some remaining contribution of ions forming inner-sphere complexes was observed.

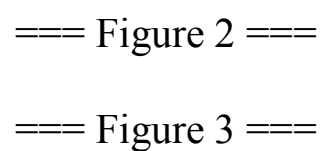

Oppositely, the lowest hydration enthalpy $\mathrm{Cs}^{+}$ions had a tendency to remain close to the surface (Figure 3), which is in excellent agreement with other recent $\mathrm{Cs}^{+}$-smectite 
simulations (Ngouana Wakou and Kalinichev, 2014; Teich-McGoldrich et al., 2015; Zaunbrecher et al., 2015; Loganathan et al., 2016a). The distribution of $\mathrm{Cs}^{+}$in the interlayer was substantially different from those of $\mathrm{Na}^{+}$and $\mathrm{Ca}^{2+}$, which were generally quite similar to each other (compare Figures 2 and 3).

\section{$\mathrm{H}_{2} \mathrm{O}$ orientation}

The contour maps of the angular distributions of the interlayer $\mathrm{H}_{2} \mathrm{O}$ dipole vectors with respect to the direction normal to the surface ( $\alpha$ angle) plotted in a function of the distance $z$ from the surface (Figure 2) enabled the distinction of the two preferred surfaceoriented types of water molecules marked in Figure 1. The predominantly bidentate population was located closer to the surface at $z \sim 2.0 \AA$ and $\alpha \sim 0-30^{\circ}$, similarly to ideal theoretical values (observed in smectites with charge 0.5). A more distant and more pronounced monodentate population was at distances $z \sim 2.8 \AA$ and oriented in a broad range of angles between $30^{\circ}$ and $80^{\circ}$ with a maximum at $\alpha \sim 55^{\circ}$, which matches the ideal theoretical value for one $\mathrm{OH}$ vector pointing perpendicularly to the smectite surface (half of the $105^{\circ}$ angle of $\mathrm{H}_{2} \mathrm{O}$ ). For higher hydration levels, a third population of water molecules was observed closer to the middle of the interlayer. The orientational distribution of this population depended significantly on both, the hydration level of the specific smectite and the type of the interlayer cation. The latter dependence is observed clearly when comparing the distribution in Mtm05 for the same hydration levels but different interlayer cations (Figures 2 and 3).

The presence of monodentate $\mathrm{H}_{2} \mathrm{O}$ was ubiquitous. This sub-population was abundantly visible for all smectites, all cations and all hydration levels. A noticeable dependence of the location of the distribution maxima was however observed: higher average $\mathrm{H}_{2} \mathrm{O}$ dipole vector angles were observed for low charge smectites, lower hydration levels, and 
for $\mathrm{Cs}^{+}$as interlayer cation.

The bidentate $\mathrm{H}_{2} \mathrm{O}$ population was far less abundant. It could be detected only in high charge smectites and was practically absent in their low charge analogs. Layer charge increasing beyond 0.5 phuc is therefore expected increase further the amount of bidentate molecules, predicting its high contribution at charges approaching 1 phuc (mica, vermiculite), which was indeed reported by Wang et al. (2005b, 2009) and Loganathan and Kalinichev (2013) on muscovite. Further, in all smectites studied, a dependence of the bidentate $\mathrm{H}_{2} \mathrm{O}$ population on hydration level was observed: for a given smectite, the relative number of bidentate $\mathrm{H}_{2} \mathrm{O}$ decreases upon drying.

The $\mathrm{H}_{2} \mathrm{O}$ orientation also depends on the type of the interlayer cation. As the majority of $\mathrm{Cs}^{+}$cations are located close to smectite surface, a noticeable decrease of bidentate $\mathrm{H}_{2} \mathrm{O}$ population in $\mathrm{Cs}^{+}$-smectites in comparison to their $\mathrm{Na}^{+}-$and $\mathrm{Ca}^{2+}$-analogs was observed. This effect was, however, small compared to the dependence of the bidentate population on layer charge. A noticeable decrease of the maximum amplitude corresponding to monodentate population was additionally observed for the $\mathrm{Cs}^{+}$form. This decrease was accompanied by the transfer of $\mathrm{H}_{2} \mathrm{O}$ to the middle of the interlayer.

\section{Vibrational spectra of $\mathrm{H}_{2} \mathrm{O}$ in the smectite interlayer}

Kuligiewicz et al. (2015a, 2015b) found that the sharp high-frequency IR band originating from adsorbed water at $\sim 3615 \mathrm{~cm}^{-1}$ (in $\mathrm{H}_{2} \mathrm{O}$ form) and $\sim 2685 \mathrm{~cm}^{-1}$ (in $\mathrm{D}_{2} \mathrm{O}$ form) is a common feature for all hydrated smectites. Its intensity depended very little on the degree of clay hydration over a broad range of relative humidity, and its frequency exhibited a weak but systematic decrease (red-shift) upon increasing the total layer charge, with no measurable dependence on charge location. For a given layer charge, the dependence of the peak position on the field strength of the interlayer cation for high hydration enthalpy cations $\left(\mathrm{Na}^{+}, \mathrm{Ca}^{2+}\right.$, 
$\left.\mathrm{Mg}^{2+}\right)$ was negligible and only low hydration cations $\left(\mathrm{Cs}^{+}, \mathrm{K}^{+}\right)$could be distinguished. These trends were opposite to what was observed for the main $\mathrm{O}-\mathrm{H}_{\mathrm{w}}\left(\mathrm{O}-\mathrm{D}_{\mathrm{w}}\right)$ stretching envelopes, located at $\sim 3400 \mathrm{~cm}^{-1}\left(\sim 2500 \mathrm{~cm}^{-1}\right)$. The latter envelopes were known to exhibit a strong dependence of their intensity on hydration level and their position on interlayer cation, but were relatively unaffected by the smectite layer charge or charge localization (e.g., Xu et al., 2000, Madejová et al., 2002, Kuligiewicz et al., 2015a, 2015b).

Thus, the sharp high-frequency IR band observed in water vapor-saturated smectites was attributed to a mechanism that must be common to all smectites at high hydration levels, regardless of interlayer cation. In addition, the high-frequency band must account for $\mathrm{H}$ bonding interactions that are considerably weaker than those encountered in bulk $\mathrm{H}_{2} \mathrm{O}$ or aqueous solutions of common salts, and its exact position ought to show a measurable dependence on the total charge of the 2:1 layer (Kuligiewicz et al., 2015a, 2015b).

In order to provide a quantitative explanation for the aforementioned experimental phenomenology, the power spectra for hydrogen atoms of interlayer $\mathrm{H}_{2} \mathrm{O}$ molecules were calculated for different smectites and compared to the spectrum of pure bulk water, the latter calculated with the same molecular model (Figure 4).

$$
===\text { Figure } 4==
$$

The results showed that water in smectites exhibits a considerable increase of its spectral density at higher frequencies $\left(\sim 3600-3800 \mathrm{~cm}^{-1}\right)$ in respect to bulk water spectrum. The simulated spectrum of bulk water, however, shows some excessive high-frequency spectral density around $3730 \mathrm{~cm}^{-1}$, which is not observed experimentally, and indicates some limitations of the present model. Nevertheless, the shape of the power spectrum of bulk water agrees perfectly well with the spectrum obtained earlier by the same methodology (Tay and Bresme, 2006) and still represents one of the most accurate models describing the dynamics of $\mathrm{O}_{\mathrm{w}}-\mathrm{H}_{\mathrm{w}}$ stretching vibrations in water (e.g., Kalinichev, 2001; Guillot, 2002). Additionally, 
the calculated results do not show the low-frequency band at $\sim 3250 \mathrm{~cm}^{-1}$, which has been found in experimental data thus is consistent with an assignment of this band to Fermi resonance (Efimov and Naberukhin, 2002; Sovago et al., 2009).

Power spectra were also calculated for four different smectites with varying content of adsorbed water: Beid03Na, Beid05Na, Mtm03Na and Mtm05Na (Figure 5). The results showed that with increasing number of $\mathrm{H}_{2} \mathrm{O}$ molecules in the smectite interlayer the relative intensity of the lower-frequency peak at $\sim 3500 \mathrm{~cm}^{-1}$ increased. This was in qualitative agreement with the experimental observations of Kuligiewicz et al. (2015a), who reported that the higher-frequency peak is nearly fixed and the intensity of the lower-frequency peak is greatly varying with water content. In the present study, the peak intensity at $\sim 3750 \mathrm{~cm}^{-1}$ was found to depend on hydration, but this can be to some extent related to the limitations of the specific $\mathrm{H}_{2} \mathrm{O}$ molecular models used.

$$
===\text { Figure } 5==
$$

In order to further analyze the influence of different factors on the higher-frequency band, its positions was determined by fitting procedures. The low-frequency band was fitted with a mixed Gauss-Lorentz function (percentage of Lorentz function was optimized), while the higher-frequency one with a simple Gauss function. Additionally, a small combination band at $\sim 4000 \mathrm{~cm}^{-1}$ was fitted with another Gaussian (Figure 6).

$$
===\text { Figure } 6==
$$

Increasing smectite total layer charge was found to induce a noticeable red-shift of the high-frequency peak, in remarkable agreement with experiment data (Kuligiewicz et al., 2015b). This shift was observed in $\mathrm{Na}^{+}$montmorillonites and beidellites at any hydration level (Figure 7a) and also in the $2 \mathrm{~W}$ forms for any cation (Figure 7b). Only one exception was found: Mtm05Na_3W exhibited higher frequency of the sharp peak than Mtm03Na_3W. In contrary to the experimental observations (Kuligiewicz et al., 2015a), the position of the 
high-frequency peak was found to depend on charge location and water content.

$$
===\text { Figure } 7==
$$

In addition, the MD results showed a substantial difference in peak position between the $\mathrm{Na}^{+}$and $\mathrm{Ca}^{2+}$ forms of smectites (Figure 7b), which are not visible experimentally (Figure 7c, Kuligiewicz et al., 2015a). Also the peak positions of the $\mathrm{Cs}^{+}$forms exhibited trends in relation to $\mathrm{Na}^{+}$and $\mathrm{Ca}^{2+}$ forms that are different in MD than in experiment.

These discrepancies between the experimental trends and the outcome of MD simulations can be related to the approximations involved in the latter, primarily in certain features of the CLAYFF model (Cygan et al., 2004). The Lennard-Jones parameters of Ferrage et al. (2011) should be more accurately optimized, the hexagonal cavity in the tetrahedral sheet ought to have lower ditrigonal symmetry. A better description of the structure would affect the distribution and orientation of $\mathrm{H}_{2} \mathrm{O}$. The model for $\mathrm{H}_{2} \mathrm{O}$ may also have limitations and the power spectra have excessive high-frequency spectral density at $3728 \mathrm{~cm}^{-1}$. Finally, uncertainties introduced by the fitting procedure can be observed (Figure 6). In spite of all these limitations, the overall picture is relatively consistent: All the studied smectites exhibit a stretching band at lower frequencies and this band shift to lower energy upon increasing layer charge (Figure 7ab).

\section{Molecular origin of the sharp $O-D_{w} / O-H_{w}$ band}

Calculations of the power spectra of specific sub-sets of interlayer water hydrogen atoms were performed in order to explain in more detail which part of the surface $\mathrm{H}_{2} \mathrm{O}$ population is responsible for the sharp high-frequency vibrational band observed in the experimental spectra (Kuligiewicz et al., 2015a). Each subset was defined by a common range of distances from the surface, $z$, and $\mathrm{H}_{2} \mathrm{O}$ dipole orientation angle, $\alpha$ (Figure 1). A $\mathrm{H}_{2} \mathrm{O}$ molecule belongs to a certain sub-set if it is found within the same $(z, \alpha)$ range in both the first 
and the last time-window of the VACF calculation. The results for three representative smectites (Mtm03Na_2W, Beid03Na_2W and $\mathrm{Mtm} 05 \mathrm{Ca} \_2 \mathrm{~W}$ ) are presented in Figure 8. Spectral intensities were scaled by the number of $\mathrm{H}_{2} \mathrm{O}$ molecules identified in each subset in order to compare the contribution of each subset to the total spectrum.

$$
===\text { Figure } 8==
$$

This analysis demonstrates that $\mathrm{H}_{2} \mathrm{O}$ molecules at the center of the interlayer are not responsible for producing the sharp spectral feature. The latter originates instead from the overlapping contributions of both monodentate and bidentate orientations of surface $\mathrm{H}_{2} \mathrm{O}$. The contribution of the monodentate orientation is, however, much stronger because of the higher number of $\mathrm{H}_{2} \mathrm{O}$ molecules populating this sub-set. If present, bidentate $\mathrm{H}_{2} \mathrm{O}$ gives a very small, although non-negligible, contribution to the power spectrum at frequencies that are on average higher than those of the monodentate population.

Based on the correlation of IR frequency of the O-H stretching band and the length of the H-bond, $\mathrm{O}-\mathrm{H}_{\mathrm{w}} \cdots \mathrm{O}$, (Libovitzky, 1999), a peak at $\sim 3600 \mathrm{~cm}^{-1}$ may correspond to a O-

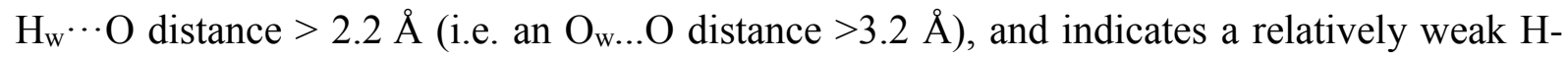
bond donated to the surface (e.g., Kalinichev, 2001; Kumar et al., 2007). Therefore, in order to obtain deeper insight into the studied problem, the distribution of the shortest $\mathrm{O}_{\mathrm{w}}-\mathrm{H}_{\mathrm{w}} \cdots \mathrm{O}_{\mathrm{b}}$ distances in the monodentate and bidentate sub-sets were calculated (Figure 8, right column). The results showed a relatively broad distribution of the distances, with the maximum for monodentate $\mathrm{H}_{2} \mathrm{O}$ at $\sim 1.9 \AA$ for $\mathrm{Beid03} \mathrm{Na}_{\mathrm{Na}}$ and $\mathrm{Mtm} 05 \mathrm{Ca} \_2 \mathrm{~W}$, and $\sim 2.0 \AA$ for Mtm03Na_2W. For comparison, in bulk liquid water the maximum of the shortest $\mathrm{O}_{\mathrm{w}}-$ $\mathrm{H}_{\mathrm{w}} \cdots \mathrm{O}_{\mathrm{w}}$ distance is at $\sim 1.8 \AA$ (e.g., Kalinichev, 2001; Kumar et al., 2007). The weighted average of the calculated $\mathrm{O}_{\mathrm{w}}-\mathrm{H}_{\mathrm{w}} \cdots \mathrm{O}_{\mathrm{b}}$ distributions is, however, a little bit greater than the maxima: $2.24 \AA$ for Beid03_Na, $2.16 \AA$ for Mtm05Ca_2W, and $2.27 \AA$ for Mtm03Na_2W, comparing to $1.95 \AA$ in bulk water. In bulk water a contribution of H-bond distances $>2.2 \AA$ 
was observed, but this is much smaller than for smectites. Low charge smectites exhibited a significantly larger contribution of weak H-bonds. For the high charge smectite Mtm05Ca_2W the contribution of weak $\mathrm{H}$-bonds due to $\mathrm{H}_{2} \mathrm{O}$ molecules in monodentate orientation was noticeably smaller. This explains the higher frequency and intensity of the high-frequency monodentate peak in the vibrational spectrum of this smectite. In the case of bidentate population, one of the $\mathrm{O}-\mathrm{H}_{\mathrm{w}} \cdots \mathrm{O}_{\mathrm{b}}$ distances had a maximum also at $\sim 1.9-2.0 \AA$, resulting in an H-bond of a comparable strength, while the second one was significantly longer and, respectively, weaker. This analysis suggests that upon increasing total layer charge the H-bond distances of the bidentate sub-set are decreasing and causing the red-shift of the calculated power spectrum.

Due to its ubiquitous presence and relative abundance, the population of monodentate surface $\mathrm{H}_{2} \mathrm{O}$ is mainly responsible for the presence of the sharp high-frequency $\mathrm{OH}$ stretching feature observed in the experiments (Kuligiewicz et al., 2015a). This is in very good agreement with earlier experimental data (e.g., Russell and Farmer 1964; Farmer and Russell 1971; Prost 1975; Suquet et al., 1977; Sposito and Prost 1982; Sposito et al., 1983) which linked the high frequency band to $\mathrm{H}_{2} \mathrm{O}$ at the surface of the interlayer, pointing one of their O$\mathrm{H}_{\mathrm{w}}$ bonds towards the siloxane surface. In certain cases the bidentate sub-population may provide a non-negligible contribution as observed for higher charged smectites, e.g., for Mtm05_Ca_2W.

\section{Possible alternative molecular mechanisms responsible for the sharp O-Dw/O-Hw band}

Evidence from MD simulations in support of the experimental data, suggested that the sharp high-frequency band in the IR spectra of hydrated smectite is clearly originating from $\mathrm{H}_{2} \mathrm{O}$ molecules oriented towards the clay surface. Can there be any other contribution to this sharp IR band? One possibility that would also be linked to surface $\mathrm{H}_{2} \mathrm{O}$, could, for example, 
involve the second $\mathrm{O}-\mathrm{H}_{\mathrm{w}}$ bond of monodentate $\mathrm{H}_{2} \mathrm{O}$, i.e. the one oriented towards the middle of the interlayer, away from the siloxane surface. As the surface $\mathrm{H}_{2} \mathrm{O}$ molecules have relatively fixed orientations, their $\mathrm{O}-\mathrm{H}_{\mathrm{w}}$ bonds that are pointing away from the surface might have a decreased number of available H-bond acceptors within a suitable range and orientation around them. Such a lower coordination could, in principle, contribute in part to the observed sharp high-frequency infrared band. To examine this possibility, the subsets representing two separate hydroxyls of the monodentate population in Mtm05Ca_2W and Mtm05Na_2W were investigated (Figure 9).

$$
===\text { Figure } 9==
$$

In the case of monodentate $\mathrm{H}_{2} \mathrm{O}$, one $\mathrm{H}$-bond is donated to the surface (thick blue rectangle in Figure 9), while the second one is donated to another $\mathrm{H}_{2} \mathrm{O}$ (dashed orange rectangle in Figure 9). The corresponding power spectra show that only the hydrogens oriented towards the surface contribute to the high-frequency band. The power spectrum of the second hydrogen resembles that of bulk water, with even a slightly higher intensity of the vibrational band at lower frequency $\sim 3500 \mathrm{~cm}^{-1}$, indicating a relatively strong H-bonding to other interlayer $\mathrm{H}_{2} \mathrm{O}$ molecules. This is additionally confirmed by comparison of the shortest $\mathrm{O}_{\mathrm{w}}-\mathrm{H}_{\mathrm{w}} \cdots \mathrm{O}_{\mathrm{w}}$ distances of this sub-population and the corresponding distances in pure water (right column in Figure 9). The two distributions are practically identical.

A second mechanism potentially responsible for the emergence of the high-frequency $\mathrm{H}_{2} \mathrm{O}$ stretching band could be related to the influence of interlayer cations. The latter could deform the H-bonding structure of $\mathrm{H}_{2} \mathrm{O}$ molecules around them and possibly induce some $\mathrm{H}$ bond breaking. A clear evidence against this possibility has been provided already in Figure 8: $\mathrm{H}_{2} \mathrm{O}$ molecules in the middle of the interlayer (red rectangle) were found not to contribute to the high-frequency band of interest. This is especially obvious in the case of Mtm05Ca_2W, where $\mathrm{H}_{2} \mathrm{O}$ molecules in the hydration shell of $\mathrm{Ca}^{2+}$ are oriented around the ions exactly in the 
center of the interlayer.

\section{Hydrogen bonding in the interlayer space of smectite}

The question regarding other possible molecular mechanisms responsible for the sharp high-frequency $\mathrm{O}-\mathrm{D}_{\mathrm{w}} / \mathrm{O}-\mathrm{H}_{\mathrm{w}}$ band can be alternatively expressed as follows: Does interlayer water contain a sub-population of $\mathrm{H}_{2} \mathrm{O}$ molecules for which the $\mathrm{O}-\mathrm{H}_{\mathrm{w}} \cdots \mathrm{O}$ distance of donated H-bonds is longer than $2.2 \AA$ (Libovitzky, 1999)? Obviously, the results of this analysis are only valid in comparison to those on pure bulk liquid water, due to the method-artificial nonnegligible contribution of weak H-bonds in the latter (see Figure 8 and 9).

To address this question, the numbers of accepted and donated H-bonds were calculated depending on the distance $z$ of the involved $\mathrm{H}_{2} \mathrm{O}$ molecules from the smectite siloxane surface. In the ordered ice structure, each $\mathrm{H}_{2} \mathrm{O}$ donates two strong $\mathrm{H}$-bonds to other $\mathrm{H}_{2} \mathrm{O}$ and also accepts two strong $\mathrm{H}$-bonds from two other $\mathrm{H}_{2} \mathrm{O}$ molecules. In liquid water, the number of donating and accepting $\mathrm{H}$-bonds formed by each $\mathrm{H}_{2} \mathrm{O}$ molecule is somewhat lower than in ice due to the molecular disorder, and depends on temperature, density, and other thermodynamic factors. The exact number of $\mathrm{H}$-bonds experienced by a $\mathrm{H}_{2} \mathrm{O}$ molecule in each situation also depends to some extent on the assumed criterion used in H-bonding calculation (see., e.g., Kalinichev, 2001; Kumar et al., 2007).

A geometric definition for counting $\mathrm{H}$-bonds (HB) was adopted from the literature (Wang et al., 2009; Loganathan and Kalinichev, 2013). According to this definition, an Hbond is assumed to exist if the $\mathrm{H} \cdots \mathrm{O}$ distance between the donor and acceptor is below $2.45 \AA$ and the angle between the $\mathrm{O}-\mathrm{H}$ and $\mathrm{O} \cdots \mathrm{O}$ vectors is below $30^{\circ}$. A systematic application of this criterion enabled the quantitative visualization of the general $\mathrm{H}$-bonding trends of interlayer $\mathrm{H}_{2} \mathrm{O}$ molecules for several model smectites (Figure 10). As expected, Hbonds donated to surface $\mathrm{O}_{b}$ atoms from both bidentate and monodentate $\mathrm{H}_{2} \mathrm{O}$ populations 
were identified in all cases (thick solid lines in Figure 10). The maximum of their distribution corresponded to the monodentate population, whereas the small shoulder closer to the surface originated from bidentate $\mathrm{H}_{2} \mathrm{O}$. Besides donating to the basal surface, both bidentate and monodentate $\mathrm{H}_{2} \mathrm{O}$ accepted $\mathrm{H}$-bonds from and donated to other $\mathrm{H}_{2} \mathrm{O}$ in the interlayer (dashed and thin solid lines, respectively in Figure 10). The maxima of the accepted and donated $\mathrm{H}$ bonding distributions corresponded clearly to the expected (e.g., Ferrage et al., 2011; Ngouana Wakou and Kalinichev, 2014) twin maxima of the $\mathrm{O}_{\mathrm{w}}$ distribution along $z$, shown previously for all $2 \mathrm{~W}$ structures (Figures 2 and 3). Subtler differences in the fractions of accepting and donating $\mathrm{H}$-bonds depended on the charge and the type of the interlayer cation (Figure 10).

\section{$===$ Figure $10==$}

The distributions of $\mathrm{H}$-bonds along $z$ (Figure 10) provide a general picture of the $\mathrm{H}$ bonding structure in smectite interlayers, but they do not directly indicate the location of particularly weak hydrogen bonds. To address this issue, the distributions of H-bonds on the basis of their strength was also calculated (Figure 11). This was achieved by modifying the aforementioned geometric definition of H-bond to probe only the relatively weak interactions having $\mathrm{O}_{\mathrm{w}}-\mathrm{H} \cdots \mathrm{O}$ distances in the range 2.2-2.7 $\AA$ and compare such a subset of the H-bonds distribution to the original definition $\left(\mathrm{O}_{\mathrm{w}}-\mathrm{H} \cdots \mathrm{O}\right.$ distance $\left.<2.45 \AA\right)$. In both cases the H$\mathrm{O}_{\mathrm{w}} \cdots \mathrm{O}$ angle was kept $<30^{\circ}$. The plots in Figure 11 show only the average distributions of $\mathrm{H}$ bonds experienced by each $\mathrm{H}_{2} \mathrm{O}$ molecule, and therefore do not inform on the absolute contribution of each molecular orientation to the final spectra.

\section{$===$ Figure $11===$}

For the general case considering all possible H-bonds in the system (Figure 11a), the number of accepted $\mathrm{H}$-bonds per $\mathrm{H}_{2} \mathrm{O}$ molecule was found relatively constant with small dependence on the smectite charge and the type of the interlayer cation (dashed lines in Figure 
11a). The number of $\mathrm{H}$-bonds donated to basal oxygen atoms was around 2.0 per $\mathrm{H}_{2} \mathrm{O}$ molecule for the bidentate orientation and slightly below 1.0 for the monodentate orientation for all types of simulated smectite systems (thick solid lines in Figure 11a). The number of Hbonds per $\mathrm{H}_{2} \mathrm{O}$ donated to other $\mathrm{H}_{2} \mathrm{O}$ was independent of charge and interlayer cation (thin solid line in Figure 11a).

The average number of weak $\mathrm{H}$-bonds calculated according to the modified geometric criterion also did not show substantial dependence on the type of smectite (Figure 11). The weakest H-bonds (0.8-1.0 of donated $\mathrm{H}$-bonds per $\mathrm{H}_{2} \mathrm{O}$; thick solid line in Figure 11b) was clearly attributed to the bidentate orientation, but some contribution from the monodentate population, amounting to $\sim 0.3$ donated $\mathrm{H}$-bonds per $\mathrm{H}_{2} \mathrm{O}$ was also observed. For comparison, the average number of weak H-bonds in bulk liquid water, calculated using the same criteria was $\sim 0.17$ per molecule. Therefore, only the fraction of weak H-bonds that is in excess of the value of $\sim 0.17$ per molecule can be considered as contributing to the sharp high-frequency vibrational band. In agreement with the calculated power spectra, these H-bonds are solely due to the bidentate and monodentate populations in the vicinity of the surface and no contribution from the central part of the interlayer was found.

\section{CONCLUSIONS}

to the siloxane surface are the only species contributing to the experimentally observed sharp high-frequency $\mathrm{O}-\mathrm{H}_{\mathrm{w}}$ stretching band of smectites (Kuligiewicz et al., 2015a, Kuligiewicz et al., 2015b). The number of interlayer $\mathrm{H}_{2} \mathrm{O}$ molecules in the monodentate orientation greatly exceeds that in the bidentate orientation and is, thus, the predominant contributor to the highfrequency vibrational band. 
(2) In the bidentate orientation each $\mathrm{H}_{2} \mathrm{O}$ molecule donates two hydrogen bonds to the

surface: one relatively strong, and another much weaker, while in the monodentate orientation it donates only one relatively weak H-bond to the surface.

(3) Increasing total layer charge leads to increasing number of bidentate molecules, but also to decreasing of $\mathrm{O}_{\mathrm{w}}-\mathrm{H} \cdots \mathrm{O}_{\mathrm{b}}$ distances for both monodentate and bidentate populations. Both factors are responsible for the red-shift of the sharp high-frequency band in smectites upon increasing the layer charge.

(4) The experimentally observed low sensitivity of the position of the high-frequency vibrational band on the type of the $\left(\mathrm{Na}^{+}\right.$or $\left.\mathrm{Ca}^{2+}\right)$ high hydration enthalpy interlayer cation remains unexplained. The differentiation of $\mathrm{Cs}^{+}$from $\mathrm{Na}^{+}$or $\mathrm{Ca}^{2+}$ may be due to its tendency to displace surface $\mathrm{H}_{2} \mathrm{O}$ and form inner-sphere complexes with the siloxane surface as suggested by Kuligiewicz et al. (2015a), but further simulation work is needed to account for the experimental data on $\mathrm{Cs}^{+}$smectites.

(5) The presence of the sharp high-frequency vibrational band in experimental and simulated spectra can be considered as a strong evidence of intrinsic hydrophobicity of the smectite siloxane surface within the studied range of layer charge (0.3-0.5 phuc), independent on the specific charge localization in the clay structure.

\section{ACKNOWLEDGMENTS}

This work was supported by the project ATLAB (FP7-REGPOT-2011-1 No. 285989) funded by the European Union. MS also acknowledges NCN (grant 2012/05/B/ST10/01948), which provided IGS PAS with a high-performance computing server and also PLGRID infrastructure. AGK acknowledges the support of the industrial chair "Storage and Disposal of Radioactive Waste" at the Ecole des Mines de Nantes, funded by ANDRA, Areva, and 
587 EDF. VG and GDC acknowledge partial support from project KRHPIS 447963 -Polynano 588 (GSRT, TPCI-NHRF).

589 
Allen, M.P. and Tildesley, D.J. (1987) Computer Simulation of Liquids. Oxford University Press, New York, 385pp.

Arab, M., Bougeard, D., and Smirnov, K.S. (2003) Structure and dynamics of the interlayer water in an uncharged $2: 1$ clay. Physical Chemistry Chemical Physics, 5, 4699-4707.

Boek, E.S., Coveney, P.V., and Skipper, N.T. (1995) Monte Carlo molecular modeling studies of hydrated Li-, Na-, and K-smectites: Understanding the role of potassium as a clay swelling inhibitor. Journal of the American Chemical Society, 117, 12608-12617.

Boek, E.S. and Sprik, M. (2003) Ab initio molecular dynamics study of the hydration of a sodium smectite clay. Journal of Physical Chemistry B, 107, 3251-3256.

Bridgeman, C.H. and Skipper, N.T. (1997) A Monte Carlo study of water at an uncharged clay surface. Journal of Physics-Condensed Matter, 9, 4081-4087.

Cariati, F., Erre, L., Micera, G., Piu, P., and Gessa, C. (1981) Water molecules and hydroxyl groups in montmorillonites as studied by near infrared spectroscopy. Clays and Clay Minerals, 29, 157-159.

Cariati, F., Erre, L., Micera, G., Piu, P., and Gessa, C. (1983) Polarization of water molecules in phyllosilicates in relation to exchange cations as studied by near infrared spectroscopy. Clays and Clay Minerals, 31, 155-157.

Cases, J.M., Berend, I., Francois, M., Uriot, J.P., Michot, L.J., and Thomas, F. (1997) Mechanism of adsorption and desorption of water vapor by homoionic montmorillonite. 3. The $\mathrm{Mg}^{2+}, \mathrm{Ca}^{2+}, \mathrm{Sr}^{2+}$ and $\mathrm{Ba}^{2+}$ exchanged forms. Clays and Clay Minerals, 45, 8-22.

Chang, F.R.C., Skipper, N.T., and Sposito, G. (1995) Computer simulation of interlayer molecular structure in sodium montmorillonite hydrates. Langmuir, 11, 2734-2741.

Churakov, S.V. (2006) Ab initio study of sorption on pyrophyllite: Structure and acidity of the 
edge sites. Journal of Physical Chemistry B, 110, 4135-4146.

Cygan, R.T., Liang, J.J., and Kalinichev, A.G. (2004) Molecular models of hydroxide, oxyhydroxide, and clay phases and the development of a general force field. Journal of Physical Chemistry B, 108, 1255-1266.

Dazas, B., Ferrage, E., Delville, A., and Lanson, B. (2014) Interlayer structure model of trihydrated low-charge smectite by X-ray diffraction and Monte Carlo modeling in the Grand Canonical ensemble. American Mineralogist, 99, 1724-1735.

Dazas, B., Lanson, B., Delville, A., Robert, J.L., Komarneni, S., Michot, L.J., and Ferrage, E. (2015) Influence of tetrahedral layer charge on the organization of interlayer water and ions in synthetic Na-saturated smectites. Journal of Physical Chemistry C, 119, 41584172.

Efimov, Y.Y. and Naberhukhin, Y.I. (2002) On the interrelation between frequencies of stretching and bending vibrations in liquid water. Spectrochimica Acta A, 58, 519 524.

Farmer, V.C. and Russell, J.D. (1971) Interlayer complexes in layer silicates: The structure of water in lamellar ionic solutions. Transactions of the Faraday Society, 67, 2737-2749.

Ferrage, E., Lanson, B., Sakharov, B.A., and Drits, V.A. (2005) Investigation of smectite hydration properties by modeling experimental X-ray diffraction patterns: Part I. Montmorillonite hydration properties. American Mineralogist, 90, 1358-1374.

Ferrage, E., Lanson, B., Sakharov, B.A., Geoffroy, N., Jacquot, E., and Drits, V.A. (2007) Investigation of dioctahedral smectite hydration properties by modeling of X-ray diffraction profiles: Influence of layer charge and charge location. American Mineralogist, 92, 1731-1743.

Ferrage, E., Sakharov, B.A., Michot, L.J., Delville, A., Bauer, A., Lanson, B., Grangeon, S., Frapper, G., Jiménez-Ruiz, M., and Cuello, G.J. (2011) Hydration properties and inter- 
layer organization of water and ions in synthetic Na-smectite with tetrahedral layer charge. Part 2. Toward a precise coupling between molecular simulations and diffraction data. Journal of Physical Chemistry C, 115, 1867-1881.

Greathouse, J.A. and Sposito, G. (1998) Monte Carlo and molecular dynamics studies of interlayer structure in $\mathrm{Li}\left(\mathrm{H}_{2} \mathrm{O}\right)_{3}$-smectites. Journal of Physical Chemistry B, 102, 24062414.

Greathouse, J.A., Durkin, J.S., Larentzos, J.P., and Cygan, R.T. (2009) Implementation of a Morse potential to model hydroxyl behavior in phyllosilicates. Journal of Chemical Physics, 130, 134713.

Greathouse, J.A., Hart, D.B., Bowers, G.M., Kirkpatrick, R.J., and Cygan, R.T. (2015) Molecular simulation of structure and diffusion at smectite-water interfaces: Using expanded clay interlayers as model nanopores. Journal of Physical Chemistry C, 119, $17126-17136$.

Guillot, B. (2002) A reappraisal of what we have learnt during three decades of computer simulations on water. Journal of Molecular Liquids, 101, 219-260.

Jaynes, W.F. and Boyd, S.A. (1991) Hydrophobicity of siloxane surfaces in smectites as revealed by aromatic hydrocarbon adsorption from water. Clays and Clay Minerals, 39, 428-436.

Kalinichev, A.G. (2001) Molecular simulations of liquid and supercritical water: Thermodynamics, structure, and hydrogen bonding. Reviews in Mineralogy and Geochemistry, 42, 83-129.

Kleinhesselink, D. and Wolfsberg, M. (1992) The evaluation of power spectra in molecular dynamics simulations of anharmonic solids and surfaces. Surface Science, 262, 189207.

Kuligiewicz, A., Derkowski, A., Szczerba, M., Gionis, V., and Chryssikos, G.D. (2015a) 

29.

Kuligiewicz, A., Derkowski, A., Emmerich, K., Christidis, G. E., Tsiantos, C., Gionis, V., and Chryssikos, G. D. (2015b) Measuring the Layer Charge of Dioctahedral Smectite by O-D Vibrational Spectroscopy. Clays and Clay Minerals, 63, 443-456.

Kumar, R., Schmidt, J.R., and Skinner, J.L. (2007) Hydrogen bonding definitions and dynamics in liquid water. Journal of Chemical Physics, 126, 204107-12.

Lee, J.H. and Guggenheim, S., (1981) Single crystal X-ray refinement of pyrophyllite-1Tc. American Mineralogist, 66, 350-357.

Libowitzky, E. (1999) Correlation of O-H stretching frequencies and O-H $\cdots$ O bond lengths in minerals. Monatshefte für Chemie, 130, 1047-1059.

Loganathan, N. and Kalinichev, A.G. (2013) On the hydrogen bonding structure at the aqueous interface of ammonium-substituted mica: A molecular dynamics simulation. Zeitschrift für Naturforschung A, 68, 91-100.

Loganathan, N., Yazaydin, A.O., Bowers, G.M., Kalinichev, A.G., and Kirkpatrick, R.J. (2016a) Structure, energetics, and dynamics of $\mathrm{Cs}^{+}$and $\mathrm{H}_{2} \mathrm{O}$ in hectorite: Molecular dynamics simulations with an unconstrained substrate surface. Journal of Physical Chemistry C, 120, 10298-10310.

Loganathan, N., Yazaydin, A.O., Bowers, G.M., Kalinichev, A.G., and Kirkpatrick, R.J. (2016b) Cation and water structure, dynamics, and energetics in smectite clays: A molecular dynamics study of Ca-hectorite. Journal of Physical Chemistry C, 120, 12429-12439.Löwenstein, W. (1954) The distribution of aluminum in the tetrahedral of silicates and aluminates, American Mineralogist, 39, 92-96.

Madejová, J., Janek, M., Komadel, P., Herbert, H.-J., and Moog, H.C. (2002) FTIR analyses of water in MX-80 bentonite compacted from high salinary salt solution systems. 
Applied Clay Science, 20, 255-271.

Marry, V., Rotenberg, B., and Turq, P. (2008) Structure and dynamics of water at a clay surface from molecular dynamics simulation. Physical Chemistry Chemical Physics, 10, 4802-4813.

Marry, V., Dubois, E., Malikova, N., Breu, J., and Haussler, W. (2013) Anisotropy of water dynamics in clays: Insights from molecular simulations for experimental QENS analysis. Journal of Physical Chemistry C, 117, 15106-15115.

Michot, L.J., Villieras, F., Francois, M., Yvon, J., Le Dred, R., and Cases, J.M. (1994) The structural microscopic hydrophilicity of talc. Langmuir, 10, 3765-3773.

Morrow, C.P., Yazaydin, A.O., Krishnan, M., Bowers, G.M., Kalinichev, A.G., and Kirkpatrick, R.J. (2013) Structure, energetics, and dynamics of smectite clay interlayer hydration: molecular dynamics and metadynamics investigation of Na-hectorite. Journal of Physical Chemistry C, 117, 5172-5187.

Ngouana Wakou, B.F. and Kalinichev, A.G. (2014) Structural arrangements of isomorphic substitutions in smectites: Molecular simulation of the swelling properties, interlayer structure, and dynamics of hydrated Cs-montmorillonite revisited with new clay models. Journal of Physical Chemistry C, 118, 12758-12773

Ortega-Castro, J., Hernández-Haro, N., Dove, M.T., Hernández-Laguna, A., and SaínzDiaz, C.I. (2010) Density functional theory and Monte Carlo study of octahedral cation ordering of $\mathrm{Al} / \mathrm{Fe} / \mathrm{Mg}$ cations in dioctahedral 2:1 phyllosilicates. American Mineralogist, 95, 209-220.

Plimpton, S. (1995) Fast parallel algorithms for short-range molecular dynamics. Journal of Computational Physics, 117, 1-19.

Praprotnik, M., Janezic, D., and Mavri, J. (2004) Temperature dependence of water vibrational spectrum: A molecular dynamics simulation study. Journal of Physical 
Prost, R. (1975) Interactions between adsorbed water molecules and the structure of clay minerals: Hydration mechanism of smectites. Proceedings of International Clay Conference of The Clay Minerals Society, Mexico City, 351-359.

Rotenberg, B., Patel, A.J., and Chandler, D. (2011) Molecular explanation for why talc surfaces can be both hydrophilic and hydrophobic. Journal of the American Chemical Society, 133, 20521-20527.

Russell, J.D. and Farmer, V.C. (1964) Infrared spectroscopic study of the dehydration of montmorillonite and saponite. Clay Minerals Bulletin, 5, 443-464.

Sato, T., Watanabe, T., and Otsuka, R. (1992) Effects of layer charge, charge location, and energy change on expansion properties of dioctahedral smectites. Clays and Clay Minerals, 40, 103-113.

Skipper, N.T., Soper, A.K., and McConnell, J.D.C. (1991) The structure of interlayer water in vermiculite. Journal of Chemical Physics, 94, 5751-5760.

Sobolev, O., Favre Buivin, F., Kemner, E., Russina, M., Beuneu, B., Cuello, G.J., and Charlet, L. (2010) Water-clay surface interaction: A neutron scattering study. Chemical Physics, 374, 55-61.

Šolc, R., Gerzabek, M.H., Lischka, H., and Tunega, D. (2011) Wettability of kaolinite (001) surfaces - Molecular dynamic study. Geoderma, 169, 47-54.

Sovago, M., Kramer Campen, R.K., Bakker H.J., and Bonn, M. (2009) Hydrogen bonding strength of interfacial water determined with surface sum-frequency generation. Chemical Physics Letters, 470, 7 - 12.

Sposito, G. and Prost, R. (1982) Structure of water adsorbed on smectites. Chemical Reviews, 82, 554-573.

Sposito, G., Prost, R., and Gaultier, J.-P. (1983) Infrared spectroscopic study of adsorbed 
water on reduced-charge Na/Li-montmorillonites. Clays and Clay Minerals, 31, 9-16.

Sposito, G., Skipper, N.T., Sutton, R., Park, S-H., Soper, A.K., and Greathouse, J.A. (1999) Surface geochemistry of clay minerals. Proceedings of National Academy of Science USA, 96, 3358-3364.

Suquet, H., Prost, R., and Pezerat, H. (1977). Etude par la spectroscopie infrarouge de l' eau adsorbée par la saponite-calcium. Clay Minerals, 12, 113-125.

Suzuki, S. and Kawamura, K. (2004) Study of vibrational spectra of interlayer water in sodium beidellite by molecular dynamics simulations. Journal of Physical Chemistry $B, \mathbf{1 0 8}, 13468-13474$.

Środoń, J. and McCarty, D.K. (2008) Surface area and layer charge of smectite from CEC and EGME/ $\mathrm{H}_{2} \mathrm{O}$ retention measurements. Clays and Clay Minerals, 56, 155-174.

Szczerba, M., Kłapyta, Z., and Kalinichev, A.G. (2014) Ethylene glycol intercalation in smectites. Molecular dynamics simulation studies. Applied Clay Science, 91, 87-97.

Tay, K. and Bresme, F. (2006) Hydrogen bond structure and vibrational spectrum of water at a passivated metal nanoparticle. Journal of Materials Chemistry, 16, 1956-1962.

Teich-McGoldrick, S.L., Greathouse, J.A., Jové-Colón, C.F., and Cygan, R.T. (2015) Swelling properties of montmorillonite and beidellite clay minerals from molecular simulation: Comparison of temperature, interlayer cation, and charge location effects. Journal of Physical Chemistry C, 119, 20880-20891.

Toukan, K. and Rahman, A. (1985) Molecular-dynamics study of atomic motions in water. Physical Review B, 31, 2643-2648.

Tunega, D., Gerzabek, M.H. and Lischka, H. (2004) Ab initio molecular dynamics study of a monomolecular water layer on octahedral and tetrahedral kaolinite surfaces. Journal of Physical Chemistry B, 108, 5930-5936. 
Wang, J.W., Kalinichev, A.G., and Kirkpatrick, R.J. (2004) Molecular modeling of the 10angstrom phase at subduction zone conditions. Earth and Planetary Science Letters, 222, 517-527.

Wang, J.W., Kalinichev, A.G., and Kirkpatrick, R.J. (2005a) Structure and decompression melting of a novel, high-pressure nanoconfined 2-D ice. Journal of Physical Chemis$\operatorname{try} B, \mathbf{1 0 9}, 14308-14313$.

Wang, J., Kalinichev, A.G., Kirkpatrick, R.J., and Cygan, R.T. (2005b) Structure, energetics, and dynamics of water adsorbed on the muscovite (001) surface: a molecular dynamics simulation. The Journal of Physical Chemistry B, 109, 15893-15905.

Wang, J., Kalinichev, A.G., and Kirkpatrick, R.J. (2009) Asymmetric hydrogen bonding and orientational ordering of water at hydrophobic and hydrophilic surfaces: A comparison of water/vapor, water/talc, and water/mica interfaces. Journal of Physical Chemistry $C, \mathbf{1 1 3}, 11077-11085$.

Xu, W., Johnston, C.T., Parker, P., and Agnew, S.F. (2000) Infrared study of water sorption on Na-, Li-, Ca- and Mg-exchanged (SWy-1 and SAz-1) montmorillonite. Clays and Clay Minerals, 48, 120-131.

Zaunbrecher, L.K., Cygan, R.T., and Elliott, W.C. (2015) Molecular models of cesium and rubidium adsorption on weathered micaceous minerals. Journal of Physical Chemistry $A, \mathbf{1 1 9}, 5691-5700$. 
Table 1. Parameters of interatomic interactions used in present MD simulations. The modifications compared to the original CLAYFF parameters (Table 1 in Cygan et al., 2004) are highlighted in bold.

\begin{tabular}{cclc}
\hline Species & charge $(e)$ & $D_{0}(\mathrm{kcal} / \mathrm{mol})$ & $R_{0}(\AA)$ \\
\hline surface bridging O & -1.05000 & 0.1554 & $\mathbf{3 . 8 0 0 0}$ \\
surface bridging O near tetrahedral substitution & -1.16875 & 0.1554 & $\mathbf{3 . 8 0 0 0}$ \\
ordinary bridging O & -1.05000 & 0.1554 & 3.5532 \\
ordinary bridging O near tetrahedral substitution & -1.16875 & 0.1554 & 3.5532 \\
ordinary bridging O near octahedral substitution & -1.18085 & 0.1554 & 3.5532 \\
tetrahedral aluminum & 1.57500 & $1.8405 \cdot 10^{-6}$ & $\mathbf{3 . 4 5 9 6}$ \\
tetrahedral silicon & 2.10000 & $1.8405 \cdot 10^{-6}$ & $\mathbf{3 . 4 5 9 6}$ \\
octahedral aluminum & 1.05000 & $1.3298 \cdot 10^{-6}$ & 4.7943 \\
octahedral magnesium & 1.05000 & $9.0298 \cdot 10^{-7}$ & 5.9090 \\
hydroxyl oxygen & -0.95000 & 0.1554 & 3.5532 \\
hydroxyl hydrogen & 0.42500 & 0.0 & 0.0 \\
aqueous sodium ion & 1.00000 & 0.1301 & 2.6378 \\
aqueous calcium ion & 2.00000 & 0.1000 & 3.2237 \\
aqueous cesium ion & 1.00000 & 0.1000 & 4.3002 \\
\hline
\end{tabular}


$\underline{\text { Table 2. Interlayer cation and water content of the simulated clay models and the resulting basal spacing. }}$

\begin{tabular}{lccccc}
\hline Model & $n\left(\mathrm{H}_{2} \mathrm{O}\right)$ phuc & $n\left(\mathrm{H}_{2} \mathrm{O}\right) / n\left(\mathrm{M}^{+}\right)$ & $\begin{array}{c}\mathrm{H}_{2} \mathrm{O} \text { wt } \% \\
\text { normalized to the total } \\
\text { mass }\left(\text { smectite }+\mathrm{H}_{2} \mathrm{O}\right)\end{array}$ & $\begin{array}{c}\mathrm{H}_{2} \mathrm{O} \text { wt\% } \\
\text { normalized to dry } \\
\text { mass (smectite) }\end{array}$ & $\begin{array}{c}\text { calculated } \\
d_{001}(\mathrm{~A})^{*}\end{array}$ \\
\hline Beid03Na_1W & 2.5 & 8.333 & 10.93 & 12.28 & 12.99 \\
Beid03Na_2W & 5 & 16.667 & 19.71 & 24.55 & 15.94 \\
Beid03Na_3W & 7.5 & 25.0 & 26.92 & 36.83 & 18.88 \\
Beid05Na_1W & 2.5 & 5.0 & 10.82 & 12.13 & 12.76 \\
Beid05Na_2W & 5.0 & 10.0 & 19.53 & 24.26 & 15.38 \\
Beid05Na_3W & 7.5 & 15.0 & 26.68 & 36.39 & 18.34 \\
Mtm03Na_1W & 2.5 & 8.333 & 10.95 & 12.29 & 12.86 \\
Mtm03Na_2W & 5.0 & 16.667 & 19.73 & 24.58 & 15.95 \\
Mtm03Na_3W & 7.5 & 25.0 & 26.94 & 36.88 & 18.95 \\
Mtm05Na_1W & 2.5 & 5.0 & 10.84 & 12.16 & 12.58 \\
Mtm05Na_2W & 5.0 & 10.0 & 19.56 & 36.31 & 15.37 \\
Mtm05Na_3W & 7.5 & 15.0 & 26.72 & 24.61 & 18.14 \\
\hline Beid03Ca_2W & 5.0 & 33.334 & 19.75 & 24.36 & 15.82 \\
Beid05Ca_2W & 5.0 & 20.0 & 19.59 & 24.64 & 15.38 \\
Mtm03Ca_2W & 5.0 & 33.334 & 19.77 & 24.41 & 15.95 \\
Mtm05Ca_2W & 5.0 & 20.0 & 19.62 & 22.53 & 15.38 \\
Beid03Cs_2W & 5.0 & 16.667 & 18.39 & 21.13 & 16.34 \\
Beid05Cs_2W & 5.0 & 10.0 & 17.45 & 22.55 & 16.13 \\
Mtm03Cs_2W & 5.0 & 16.667 & 18.40 & 21.17 & 16.41 \\
Mtm05Cs_2W & 5.0 & 10.0 & 17.47 & & 16.14 \\
\hline${ }^{*}$ Standarddeviti & & & & \\
\hline
\end{tabular}

${ }^{*}$ Standard deviation is $\sim \pm 0.05 \AA$. 
Figure 1. A snapshot of part of the MD simulation cell for Mtm05Na_3W. $\mathrm{H}_{2} \mathrm{O}$ closer to the layer surface is oriented with two $\mathrm{O}-\mathrm{H}_{\mathrm{w}}$ bonds pointing to the surface (thin green circle), whereas $\mathrm{H}_{2} \mathrm{O}$ farther from the surface - with one $\mathrm{O}-\mathrm{H}_{\mathrm{w}}$ bond oriented towards the surface (thick blue circle). The inset shows the definition of the angle $\alpha$ formed by the $\mathrm{H}_{2} \mathrm{O}$ dipole vector and the surface normal. Vertical scale showing average distance in $z$ direction relative to the oxygens of the basal plane is shown in angstroms.

Figure 2. Dependence of the $\mathrm{H}_{2} \mathrm{O}$ dipole vector orientation contours (see Figure 1 for the definition of $\alpha$ ) on the distance from the basal surface, $z$, for various hydration levels of different $\mathrm{Na}^{+}$-smectites. The interlayer distribution of the cations is shown by solid lines (blue in the color copy). Dashed lines mark the location of the surface (basal oxygen positions).

Figure 3. Dependence of the $\mathrm{H}_{2} \mathrm{O}$ dipole orientation contours on the distance from the basal surface, $z$, for $2 \mathrm{~W}$ hydration level of $\mathrm{Ca}^{2+}$ and $\mathrm{Cs}^{+}$-smectites.

Figure 4. Power spectra for hydrogens of interlayer $\mathrm{H}_{2} \mathrm{O}$ in smectites with two hydration layers (2W) in the $\mathrm{O}-$ $\mathrm{H}_{\mathrm{w}}$ stretching range showing the effect of the total layer charge and the cation-dependence: a) $\mathrm{Na}^{+}$form, b) $\mathrm{Ca}^{2+}$ form, c) $\mathrm{Cs}^{+}$form. Increase of the spectral density at higher frequency is clearly visible in comparison with the spectrum of bulk water.

Figure 5. Power spectra for hydrogens of interlayer $\mathrm{H}_{2} \mathrm{O}$ in the $\mathrm{O}-\mathrm{H}_{\mathrm{w}}$ stretching range for $\mathrm{Na}^{+}$-beidellites (top) and $\mathrm{Na}^{+}$-montmorillonites (bottom) with different total layer charge and different water contents. The spectra were scaled by their $\mathrm{H}_{2} \mathrm{O}$ content.

Figure 6. Examples of received fitsDeconvolution of power spectra for of pure water and two representative smectites.

Figure 7. Comparison of fitted frequencies: a) dependence on water content for $\mathrm{Na}^{+}$-smectites in $\mathrm{MD}$; b) dependence on interlayer cation for $2 \mathrm{~W}$ forms in $\mathrm{MD} ; \mathrm{c}$ ) in comparison to c) results from Kuligiewicz et al. (2015a). To obtain frequencies for $\mathrm{H}_{2} \underline{\mathrm{O}}$, the experimental values for $\mathrm{D}_{2} \underline{\mathrm{O} \text { were scaled by factor of }}$ $\underline{1.36 .}$

Figure $8 . \mathrm{H}_{2} \mathrm{O}$ dipole orientation with respect to the surface normal for selected sub-sets of water molecules having their $z$ and $\alpha$ values within the marked ranges (left) and power spectra of $\mathrm{O}-\mathrm{H}_{\mathrm{w}}$ stretching vibrations calculated for each individual sub-set (center): thin green - bidentate population, thick blue monodentate population, dashed red - water in the center of interlayer. Right column - the distributions of the shortest $\mathrm{H}$-bonding distances of interfacial $\mathrm{H}_{2} \mathrm{O}$ molecules with basal oxygens $\left(\mathrm{O}_{\mathrm{w}}-\mathrm{H}_{\mathrm{w}} \cdots \mathrm{O}_{\mathrm{b}}\right)$ in the bidentate and monodentate orientations, compared to distribution of $\mathrm{O}_{\mathrm{w}}-\mathrm{H}_{\mathrm{w}} \cdots \mathrm{O}_{\mathrm{w}}$ distances in pure water.

Figure 9. Orientation of the $\mathrm{O}-\mathrm{H}_{\mathrm{w}}$ vector of interfacial $\mathrm{H}_{2} \mathrm{O}$ with respect to the surface normal $(\beta)$ at various distances, $z$, from the basal surface of Mtm05Ca_2W and Mtm05Na_2W smectites (left). Calculated power spectra for the sub-sets of $\mathrm{H}_{2} \mathrm{O}$ molecules (color marked for the selected $\beta$ and $z$ ranges) are shown in the center. Right: the distributions of the shortest H-bonding distances of monodentate $\mathrm{H}_{2} \mathrm{O}$ with the basal oxygens $\left(\mathrm{O}_{\mathrm{w}}-\mathrm{H}_{\mathrm{w}} \cdots \mathrm{O}_{\mathrm{b}}\right)$ and/or other oxygen of $\mathrm{H}_{2} \mathrm{O}\left(\mathrm{O}_{\mathrm{w}}-\mathrm{H}_{\mathrm{w}} \cdots \mathrm{O}_{\mathrm{w}}\right)$, compared to distribution of $\mathrm{O}_{\mathrm{w}}-\mathrm{H}_{\mathrm{w}} \cdots \mathrm{O}_{\mathrm{w}}$ distances in pure water. Thin green - bidentate population, thick blue water $\mathrm{O}-\mathrm{H}_{\mathrm{w}}$ bond oriented towards the surface, dashed orange $-\mathrm{O}-\mathrm{H}_{\mathrm{w}}$ bond oriented towards the interlayer. Power spectra were scaled by the number of $\mathrm{H}_{2} \mathrm{O}$ molecules. A bulk water spectrum is also shown for comparison.

Figure 10. Distributions of $\underline{\mathrm{O}}_{\underline{\mathrm{w}}}$ atoms with $\mathrm{H}$-bonds donated and-accepted and donated by the interlayer $\mathrm{H}_{2} \mathrm{O}$ and $\mathrm{O}_{\mathrm{b}}$ in the $2 \mathrm{~W}$ smectite structures studied.

Figure 11. Distributions of $\underline{\mathrm{O}}_{\mathrm{w}}$ atoms with $\mathrm{H}$-bonds of various types (normalized per one $\mathrm{H}_{2} \mathrm{O}$ ) for the $2 \mathrm{~W}$ smectite structures studied. (a) - all H-bonds with $\mathrm{O}_{\mathrm{w}}-\mathrm{H} \cdots \mathrm{O}$ distances below $2.45 \AA$. (b) - weak (long) $\mathrm{H}$-bonds with $\mathrm{O}_{\mathrm{w}}-\mathrm{H} \cdots \mathrm{O}$ distances in the range of $2.2-2.7 \AA$. In both cases the $\mathrm{H}-\mathrm{O}_{\mathrm{w}} \cdots \mathrm{O}$ angle is $<30^{\circ}$. 


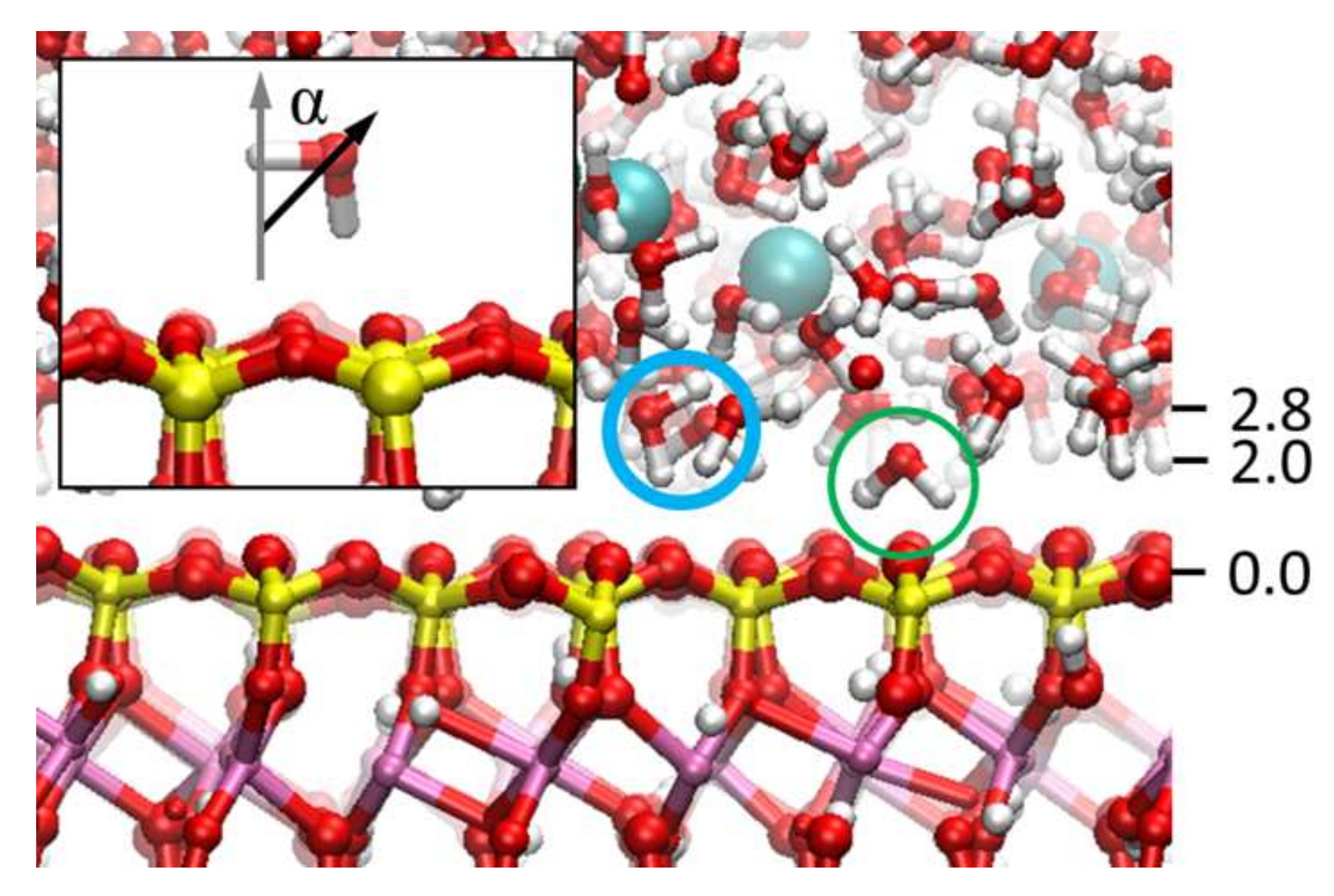



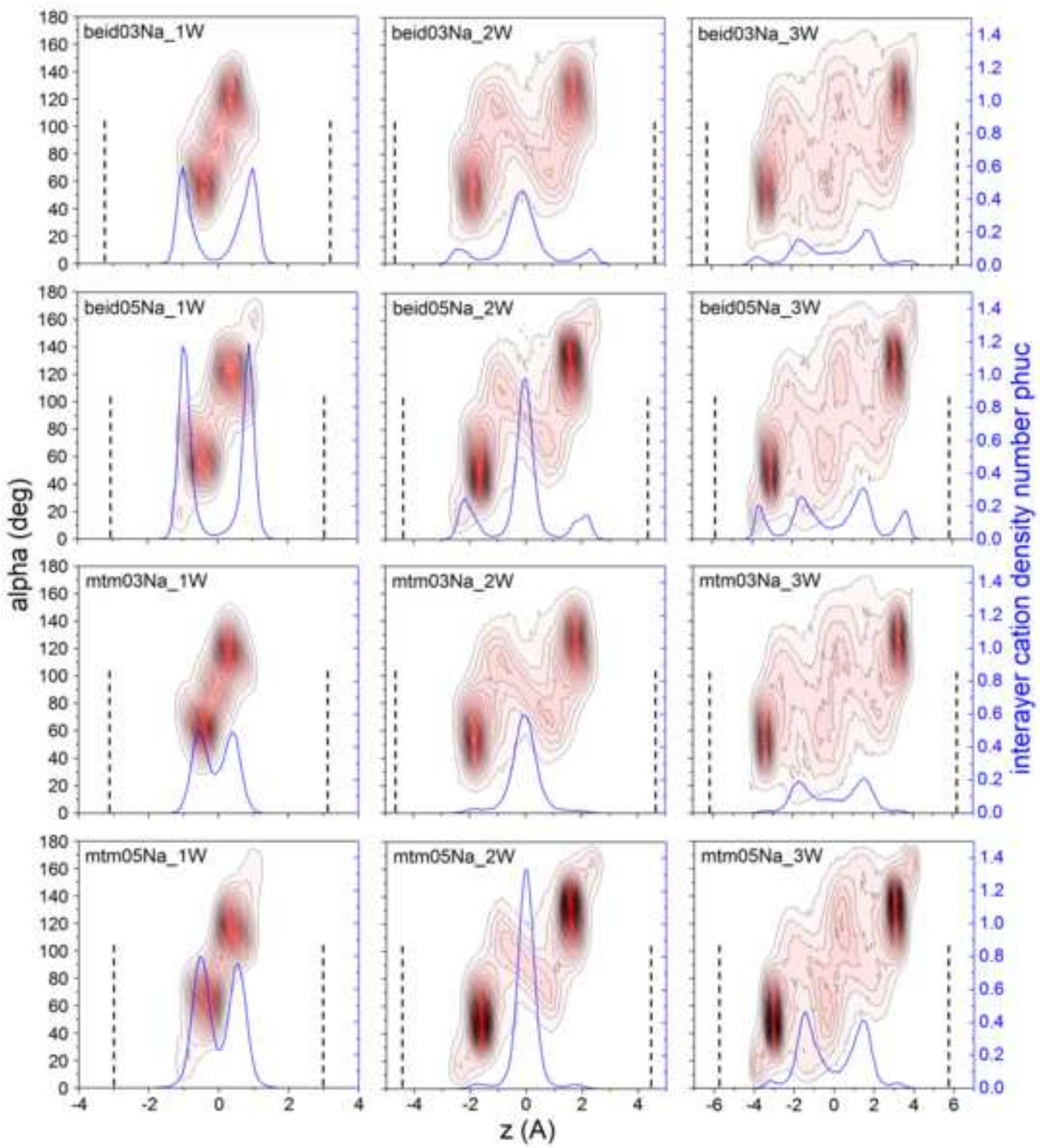

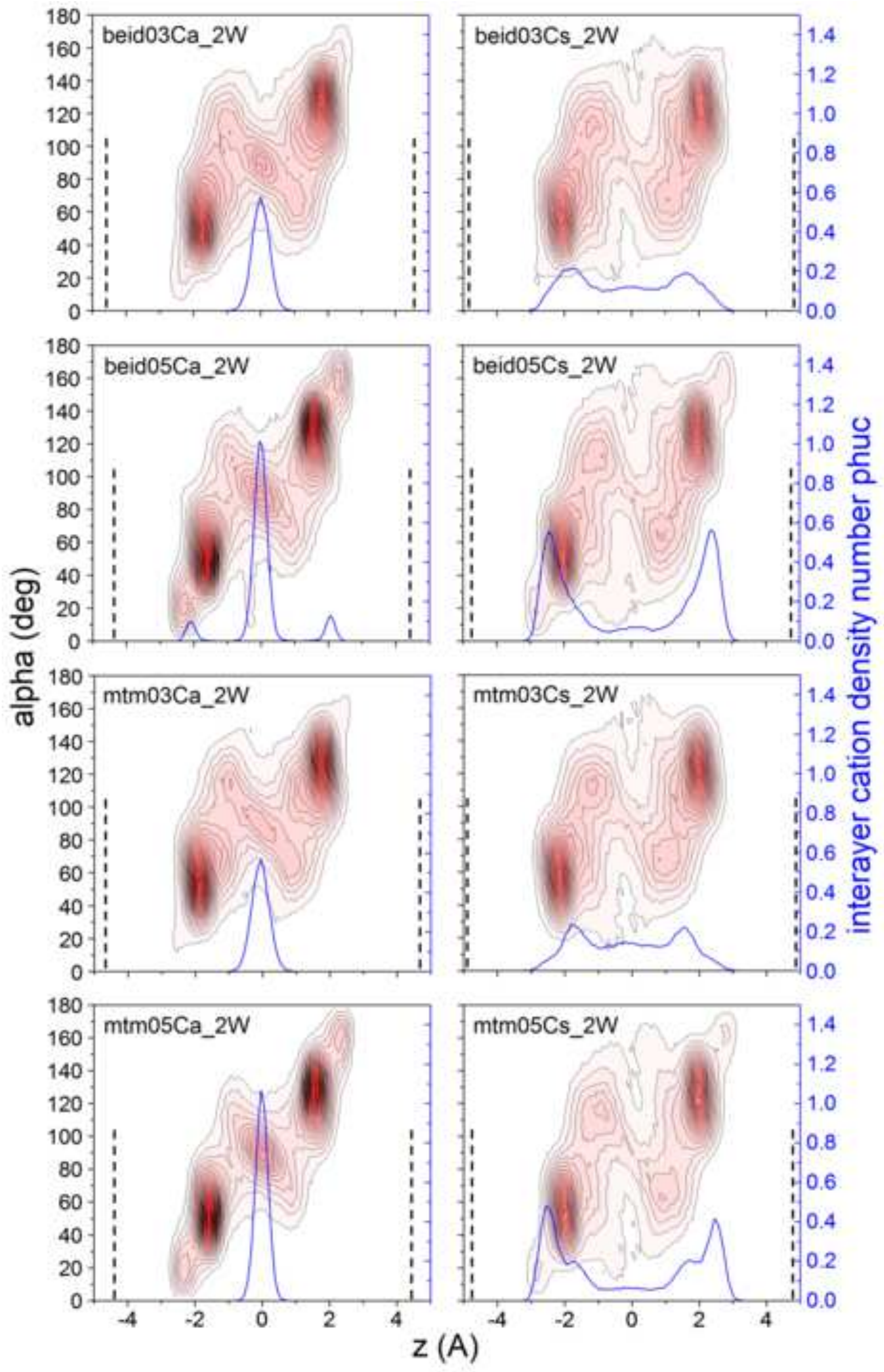

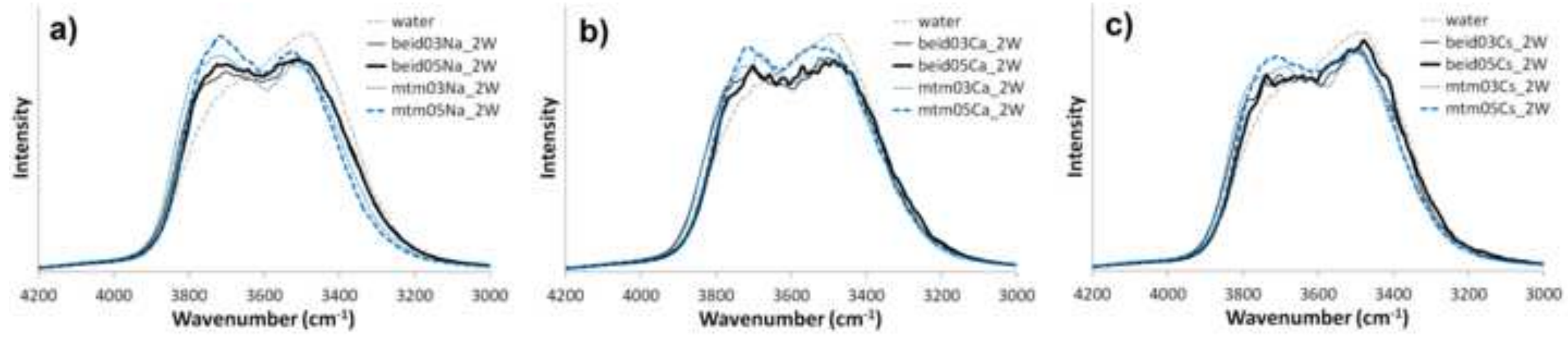

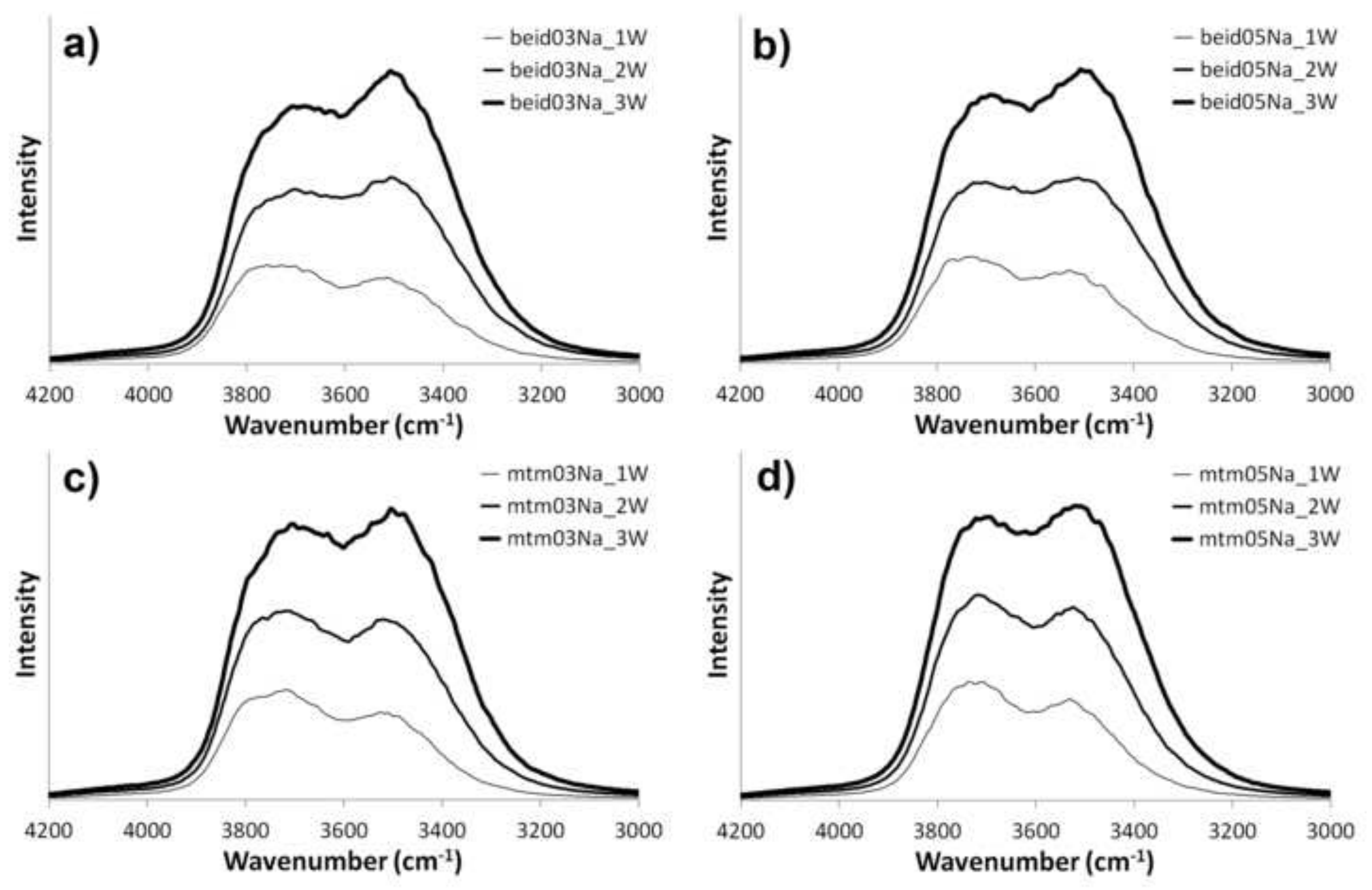

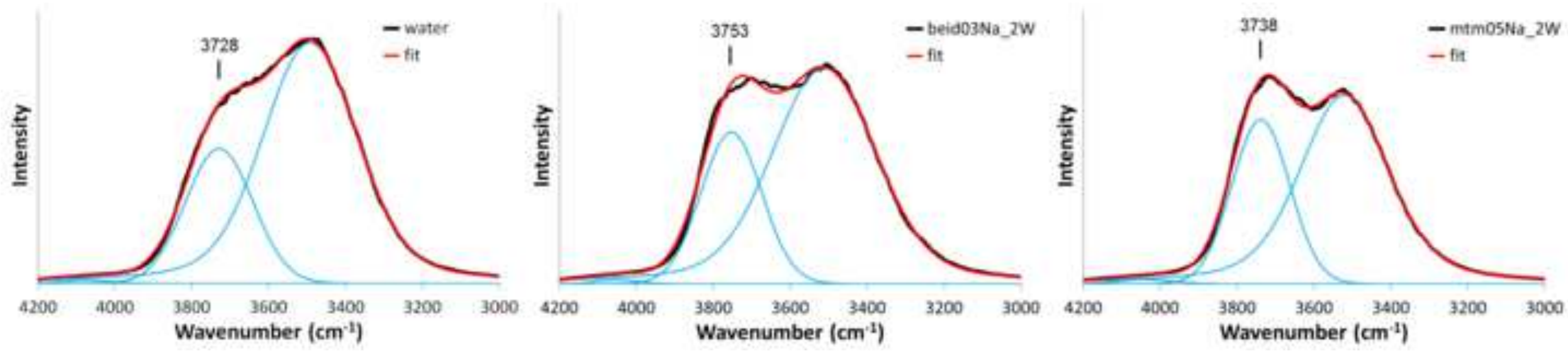

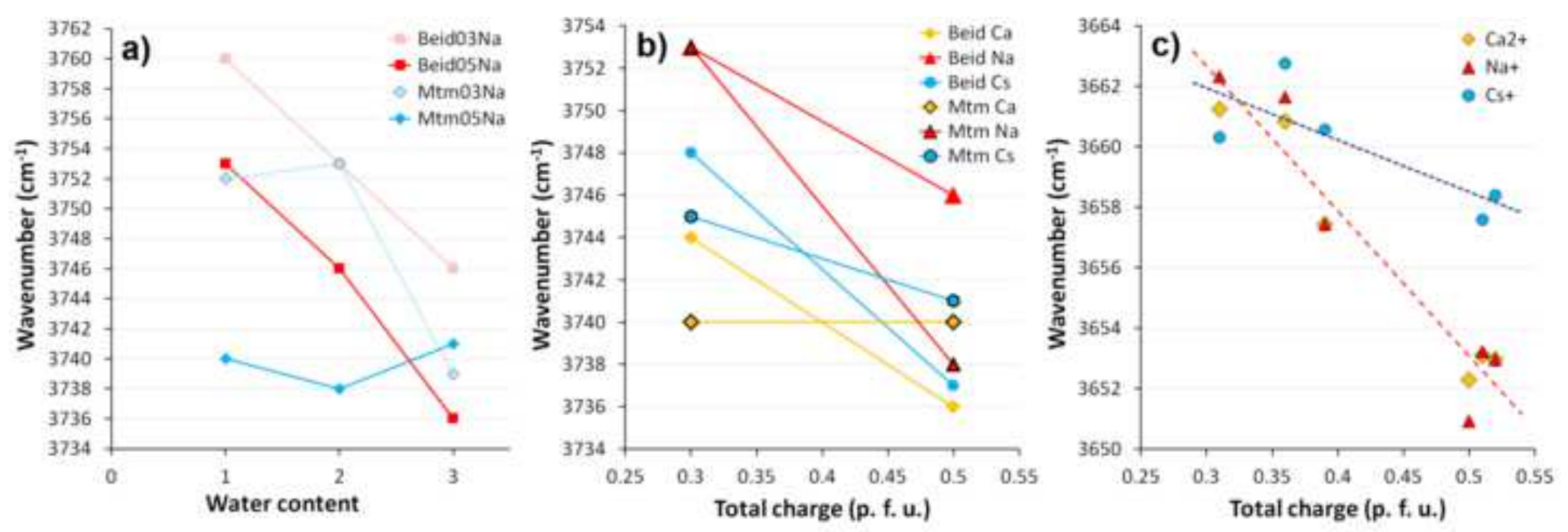

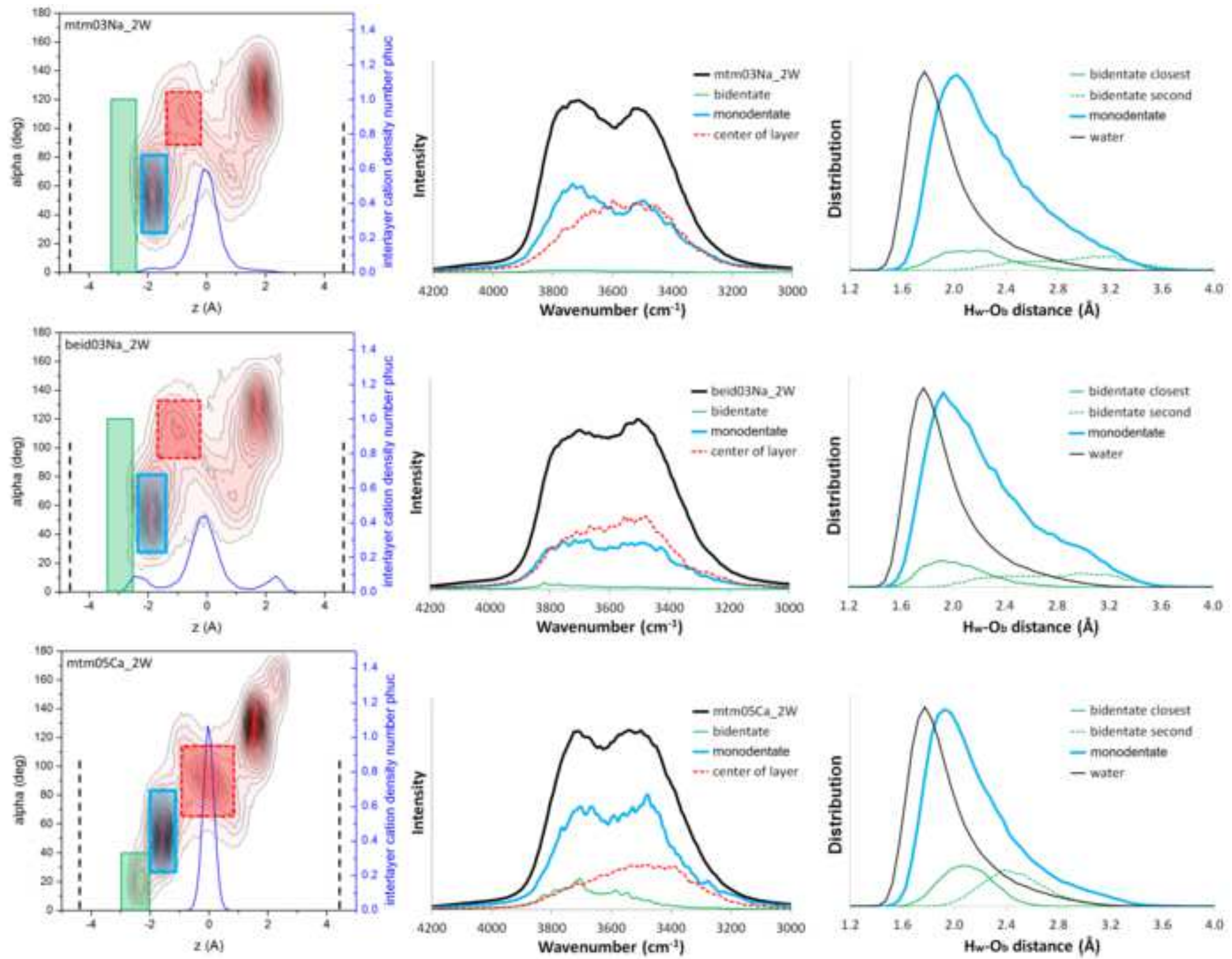

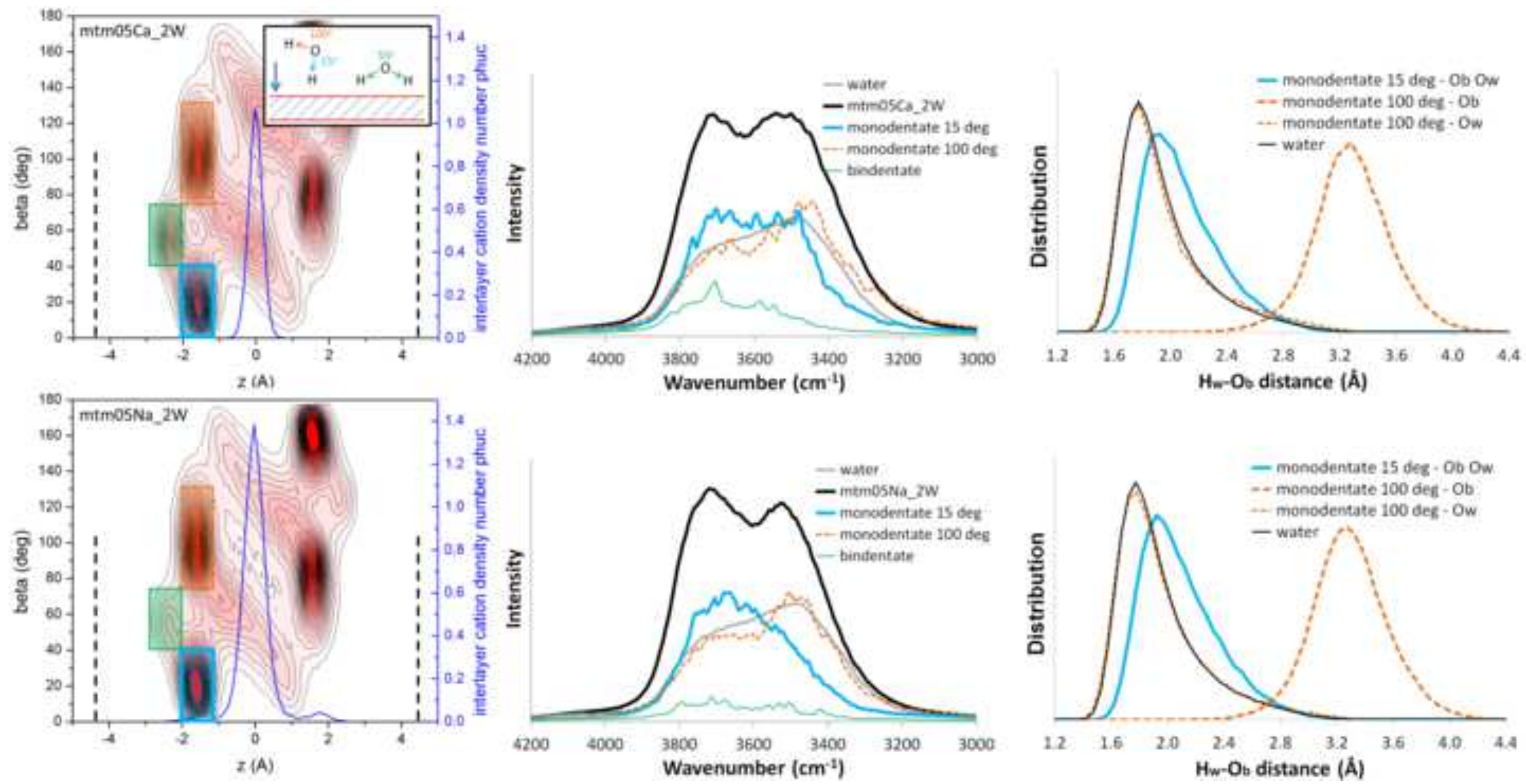

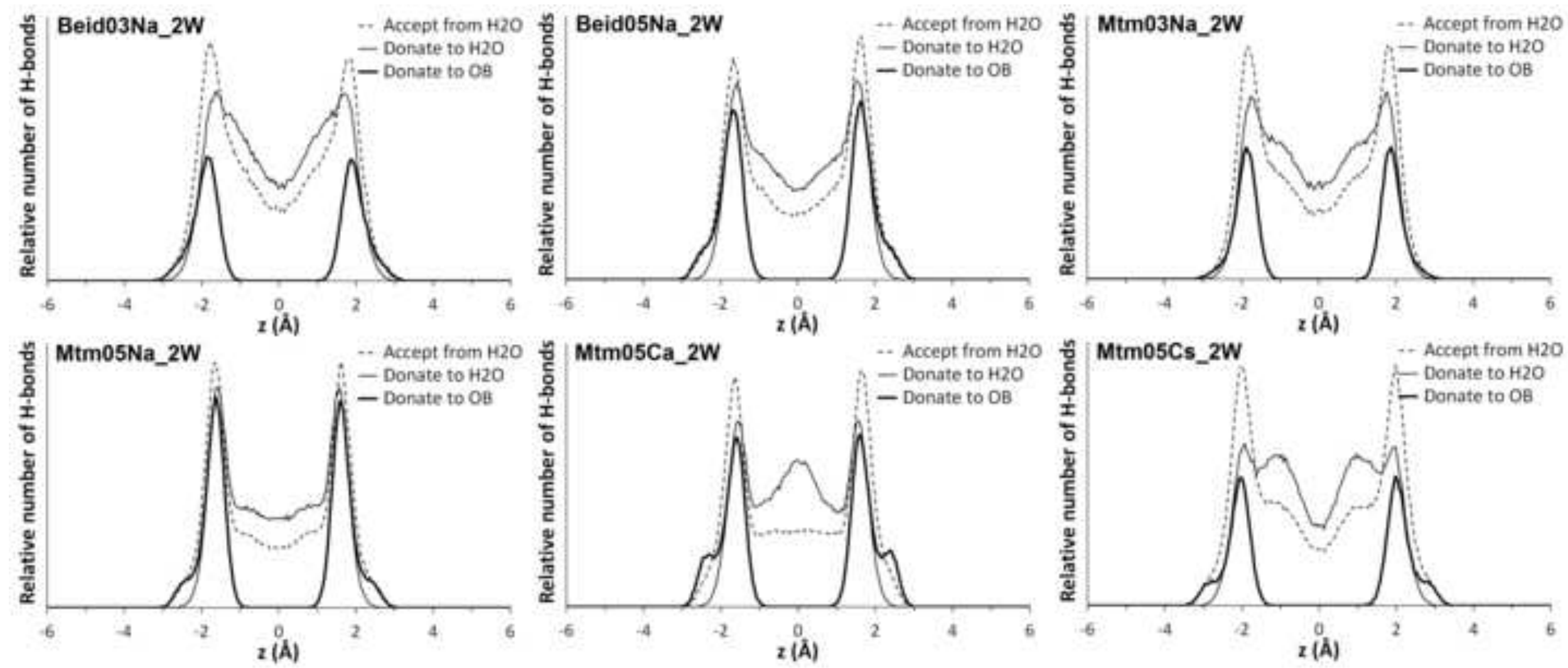

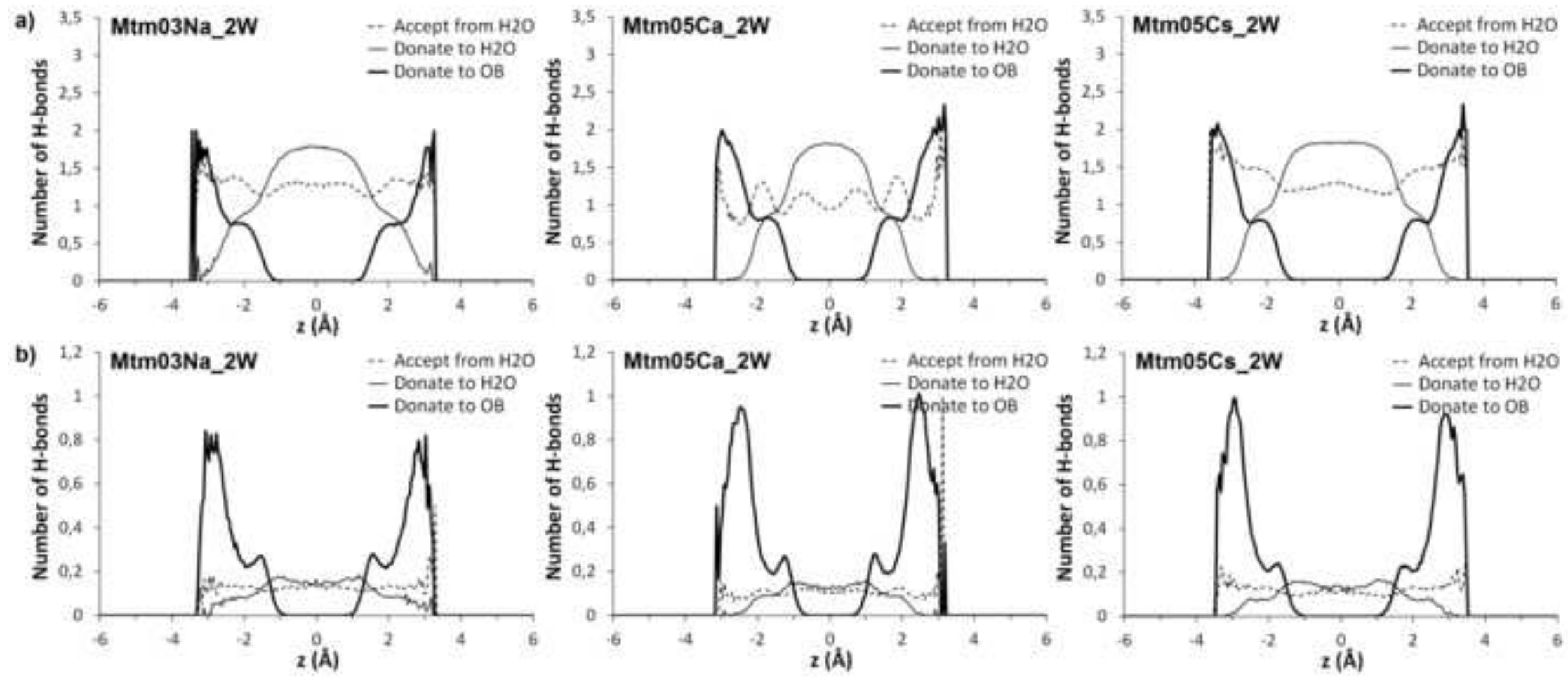